\title{
Abgründe und Hoffnungsspuren. Facetten des Bösen im zeitgenössischen Film
}

\author{
von Reinhold Zwick
}

"Ich glaube, daß Filme Kraft haben sollten.

Die Kraft des Guten und die Kraft des Bösen.

So daß man berührt wird und die Verhältnisse in Bewegung geraten." (David Lynch)1

\section{Der Horizont: Die Renaissance des Bösen}

Nicht einmal zwanzig Jahre ist es her, daß Willi Oelmüller das Schweigen seiner Disziplin, der Philosophie, „zum Thema Leiden und Böses" beklagt und auf den nicht unerheblichen Beitrag hingewiesen hat, den die Kultur- und Freizeitindustrie zur Verdrängung der ihm zugehörigen Phänomene leistet. ${ }^{2}$ Einzig die Kunst und die Religion seien es, die noch das ernsthafte Fragen nach dem Bösen wachhielten und "unzeitgemäß" gegen die vom herrschenden Bewußtsein betriebene Verdrängungsarbeit opponierten. ${ }^{3}$ Zehn Jahre später wollte Karl Heinz Bohrer selbst noch diesen Trost demontieren: Zum Bedauern über die ins 19. Jahrhundert zurückreichende "Ausblendung des Bösen durch die idealistische Philosophie, Pädagogik und Geisteswissenschaft" ${ }^{\prime 4}$ gesellt sich bei ihm der Befund eines "Defizits an Bösem", ja seiner "Tabuisierung" auch in der Kunst - als Resultat der allenthalben regierenden "Nötigung zum gesellschaftlich Guten". 5 Was die Religion anbelangt, so kommt sie bei Bohrer nur mehr als historische Größe vor. Auf dieser Linie, aber in noch apodiktischerem Ton, meint dann an der Schwelle zu den 90er Jahren Jean Baudrillard, einer der Vordenker der

Dr. theol. Reinhold Zwick ist wissenschaftlicher Assistent an der Universität Regensburg.

1 Zit. n. R. Fischer, David Lynch. Die dunkle Seite der Seele, München 1992, 253.

2 W. Oelmüller, "Zur Deutung gegenwärtiger Erfahrungen des Leidens und des Bösen", in: Concilium 11 (1975) 198-207, $198 f$.

3 Ebd., 200f.

4 K. H. Bohrer, „Das Böse - eine ästhetische Kategorie?“, in: Merkur 39 (1985) $459-473,473$.

5 K. H. Bohrer, "Die permanente Theodizee. Über das verfehlte Böse im deutschen Bewußtsein“, in: Merkur 41 (1987) 267-286, hier 281f. - Bohrer trifft sich hier in vielem mit Gedanken von Georges Bataille, wie sie dieser bes. in Die Literatur und das Böse (München 1987) entwickelt hat. Für eine instruktive Synthese von Batailles Ansatz vgl.: G. Bergfleth, „Die Souveränität des Bösen. Zu Batailles Umwertung der Moral“, in: ebd., 187-236. 
Postmoderne, daß es in unseren Tagen in der westlichen Zivilisation "keine Möglichkeit mehr gibt, Böses zu sagen", daß "die geringste Negativität durch virtuellen Konsens betäubt wird."6

Sind diese Diagnosen auch allzu forciert, und zwar nicht nur in Sachen Kunst und Religion, so ist mit der in ihnen angezeigten Abstinenz vom Problem des Bösen doch ein Grundzug eines breiten Strangs der westlichen Intelligenz markiert. Diese Abstinenz erklärt ein gutes Stück weit das Erschrecken eines Filmkritikers unserer Tage über die "weitgehende Sprachlosigkeit gegenüber dem Phänomen des Bösen und seiner Darstellung"7, während sich dieses selbst gleichzeitig mehr und mehr Raum verschafft. Denn zweifelsohne haben in den letzten Jahren die vielfältigen Erfahrungen des Abgründigen, Monströsen und Destruktiven in globaler Dimension wie auch im Bereich des individuellen Lebens dramatisch zugenommen.

In dem Maße, wie nun in der jüngeren Philosophie und Theologie - in einer Gegenbewegung zu den angedeuteten idealistischen und deontologischen Traditionen - zusehends ein erfahrungszentrierter Weg beschritten wird, konnte schließlich auch einer reflexiven Bearbeitung all der aktuellen und akuten Widerfahmisse des Bösen immer weniger ausgewichen werden. Dies begünstigte nachhaltig die gegenwärtig vielzitierte "Renaissance des Bösen", eine Entwicklung, an der gerade die nicht-theologischen akademischen Disziplinen partizipieren. ${ }^{8}$ Diese "Renaissance", die binnen weniger Jahre die eingangs skizzierten Situationsbeschreibungen umgestülpt hat, ist eines der signifikantesten Symptome der Krise einer auf die Totalherrschaft der Vernunft gegründeten Moderne und des Unbefriedigenden jener Deutungsmuster, die das Böse gänzlich in gesellschaftliche und psychologische Erklärungen auflösen wollten.

Der erste breitere Widerstand gegen eine sich omnipotent wähnende Aufklärung formierte sich freilich bereits im vergangenen Jahrhundert: Zum einen im gerade heute wieder für die Diskussion des Bösen enorm bedeutsamen Denken Sören Kierkegaards und Friedrich Nietzsches, zum anderen in der Kunst der "schwarzen Romantik"9, die durch eine über alle positiven Sinnverpflichtungen hinwegschreitende

6 J. Baudrillard, Transparenz des Bösen. Ein Essay über extreme Phänomene, Berlin 1992, 96.

7 R. Gansera, "Pharisäisches Entrüsten/Zynisches Gefallen“, in: epd Film 10 (1993) Nr. 7, 11-12, hier 12.

8 Vgl. A. Schuller/W. von Rahden (Hg.), Die andere Kraft. Zur Renaissance des Bösen, Berlin 1993; sowie C. Colpe/W. Schmidt-Biggemann (Hg.), Das Böse. Eine historische Phänomenologie des Unerklärlichen, Frankfurt/M. 1993.

9 Vgl. den immer noch sehr informativen Überblick: M. Praz, Liebe, Tod und Teufel. Die schwarze Romantik, München 1988. 
Imagination des Bösen in Wort und Bild gegen die "Entmythologisierung aller Gesellschaftsbereiche ${ }^{\mu 10}$ protestiert und den "Diskurs der rationalistisch-wissenschaftlich geprägten Moderne" 11 aufkündigt. Im Zuge der Krise des Projekts der Aufklärung, die sich auch in einer viele Lebensbereiche berührenden Rückkehr des Heiligen, einer Revision der von Max Weber konstatierten "Entzauberung“ der Welt artikuliert12, emanzipiert sich die Kunst unserer Tage mehr und mehr von der Verpflichtung auf dieses Projekt und knüpft wieder verstärkt an die Traditionen der schwarzen Romantik, an deren GrenzüberschreitungsPathos und an die Präferenz für das Sinistre an.

So überrascht es nicht, wenn die Kunst der Gegenwart in neuer Intensität von den allgegenwärtigen Erfahrungen des Bösen Zeugnis ablegt und bedrängende, bisweilen schwer erträgliche Schilderungen und Phantasmagorien desselben bereithält. Oftmals will sie dabei nicht ,nur' das Unfaßliche des Bösen in zeitnahen künstlerischen Gestaltungen greifbar werden lassen, sondern versucht auch, dieses Böse auf seine Ursprünge hin zu sondieren und bisweilen sogar Pfade seiner Überwindung anzudeuten. Dies alles gilt in besonderer Weise für die Filmkunst, der nicht zufällig von ihren Anfängen an eine besondere Affinität zum Dunklen, Dämonischen und Abgründigen nachgesagt wird 13 , und die manchem ihrer Verächter einst gar selbst als eine "Erfindung des Teufels"14 galt. Das Kino als Ganzes war schon immer ein großes Senscrium dafür, welche Erfahrungen, Ängste und Sehnsüchte die Menschen je $\mathrm{zu}$ ihrer Zeit besonders bewegen. Indem es auf die elementare Konstitution des Menschen reagiert, dem ungeachtet aller philosophischen und ideologischen Trends die Frage nach Gut und Böse und nach Sinn angesichts des Leids immer ein zentrales Problem geblieben ist, verfügt es notwendigerweise über ein ungewöhnlich reiches Ensemble an Formen der Auseinandersetzung mit dem Bösen. Allein von seinem Umfang wie von seiner Vielgestaltigkeit her legt dieses Repertoire gegen alle Tendenzen einer Verharmlosung, Minimierung oder ,Ent-Bösung, (Odo Marquardt) des Bösen nachdrücklich Widerspruch ein.

Auf narrative Weise, also in einer der biblischen - und letztlich aller ursprünglichen religiösen - Rede korrespondierenden Form,

10 K. H. Bohrer, Permanente Theodizee (Anm. 5), 272.

11 K. H. Bohrer, Das Böse (Anm. 4), 473.

12 Vgl. D. Kamper/Ch. Wulf (Hg.), Das Heilige. Seine Spur in der Moderne, Frankfurt/M. 1987; vgl. auch das gegenwärtige Interesse am Denken von René Girard, bes. an seinem Das Heilige und die Gewalt, Frankfurt/M. 1992.

$13 \mathrm{Vgl}$. die 'klassische' Studie über das deutsche expressionistische Kino: L. Eisner, Dämonische Leinwand, Frankfurt/M. 1975.

14 Vgl. R. Cosandey/A. Gaudreault/T. Gunning (Hg.), Une Invention du diable? Cinéma des premiers temps et religion - An Invention of the Devil? Religion and Early Cinema, Sainte-Foy/Lausanne 1992. 
thematisiert das Kino dieses Böse überaus oft im Rückgriff auf Elemente der alten mythischen Symbolsprachen und häufig (bewußt oder unbewußt) auch in christlichen Koordinaten, oder, vorsichtiger, in Koordinaten, die aus der theologisch-philosophischen Tradition vertraut sind. Wenn nun nicht die in der "Nichtung' des Bösen (Hegel, Barth) "sich totlaufende Sprache ${ }^{\prime \prime} 15$ der ontologisch-metaphysischen Reflexion, sondern die Sprache des Mythos die privilegierte Form des Nachdenkens über das Böse ist, und davon bin ich mit Paul Ricoeur ${ }^{16}$ überzeugt, dann dürfte gegenwärtig der große, mythengesättigte und mythenproduzierende Erzählraum ,Kino' der privilegierte Ort dieser Arbeit des Mythos sein. Der Film hat in unserem Jahrhundert die Literatur als "Domäne des Bösen" 17 abgelöst, welche in den säkularisierten Kulturen ihrerseits zuvor in mancherlei Hinsicht das Erbe der Religion angetreten hatte. ${ }^{18}$ Heute bewahrt und aktualisiert zuvorderst das Kino den Vorrat an Strukturen, Symbolen und Bildern des mythischen Denkens, der sich aus der religiösen Überlieferung aller Kulturen speist und in erstaunlicher Vielfalt auch in den Schriften des Alten und Neuen Testaments wiedergefunden werden kann. Deshalb ist die Auseinandersetzung mit dem Film für die Theologie unerläßlich: will sie sich in einer Gegenwart behaupten, in der sich Kino und Fernsehen als größte und massenwirksamste neuzeitliche Weltdeuter und (oft natürlich auch sehr sorglose) Verwalter des religiösen Menschheitserbes etabliert haben, muß sie den Dialog mit dem Film suchen. Dieser Dialog hält sie an zur permanenten Überprüfung ihrer Antworten auf die Sinnfrage und - in Konfrontation mit der zusehends universal verständlichen Sprache des Films - zur ständigen Revision ihrer eigenen ,Grammatik'.

\section{Die Achse: Das Problem der Freiheit}

Angesichts der sprichwörtlichen Vielzahl der ,Gesichter' des Bösen ist vorab zu überlegen, welche seiner Dimensionen hier näher betrachtet werden sollen. Am sinnvollsten erscheint uns eine Abblendung des von Augustinus als "malum physicum" angesprochenen Bösen (im deutschen oft mit dem Wort "Übel" bezeichnet), wie es sich etwa in Krankheit und Naturkatastrophen kristallisiert und dann die klassische

15 Dokumentation Concilium/Unter Verantwortung des Generalsekretariats, "Verführung und Verführer“, in: Concilium 6 (1970) 450-455, hier 453.

16 P. Ricoeur, Die Symbolik das Bösen. Phänomenologie der Schuld II, Freiburg-München 1971; ders., Art. "Evil", in: M. Eliade (Hg.), The Encyclopedia of Religion, Bd. 5, New York-London 1987, 199-208.

17 G. Bergfleth, Souveränität des Bösen (Anm. 5), 191f. - Die erschreckendsten Werke des Bösen finden sich freilich nach wie vor in der Literatur, wo die Imagination am zügellosesten, am wenigsten eingeengt vom Druck des Marktes und der Zensur, schweifen kann. Vgl. z. B. B. E. Ellis, American Psycho, Köln 1991 oder die Romane von Frank Harris.

18 Vgl. ebd., 193. 
Theodizee-Frage nach der "Besten aller möglichen Welten“ aufwirft, zugunsten einer Konzentration auf jene Region, die der theologischen und philosophischen Tradition christlicher Denomination noch stets als der Bereich des ,eigentlich Bösen' galt: auf das Böse, bei dem die Freiheit des Menschen mit zur Disposition steht, das Böse also im Sinne des "malum morale" (Augustinus) bzw. des "Moralisch-Bösen" (Kant). ${ }^{19}$ Stellvertretend für zahllose gleichlautende Stimmen bringt dies Walter Kasper auf den Punkt: "Die Dimension, in der das Problem des Bösen philosophisch sinnvoll verhandelt werden kann, ist die Dimension der menschlichen Freiheit." ${ }^{20}$ Denn, so kann ihm Paul Ricoeur beipflichten: "Das Böse würde aufhören, böse zu sein, wenn es aufhörte, eine Seinsweise der Freiheit zu sein, die selbst aus der Freiheit kommt.“21 Die Option auf die Möglichkeit der Freiheit, die in der liebenden, und deshalb notwendigerweise freien Zuwendung des Menschen zu Gott aufgipfelt, aber auch die Freiheit des Sich-ihm-Verweigerns einschließt, ist ein essentielles Proprium des christlichen Glaubens. ${ }^{22}$ Gegenüber einem radikalen Determinismus oder Nietzsches alles relativierender Position, die die Freiheit des Willens erst "jenseits von Gut und Böse ${ }^{\mu}$, jenseits aller moralischen Bestimmungen beginnen sieht, verbindet sich mit der Anerkennung von Freiheit und Wille gewissermaßen im ,Diesseits von Gut und Böse' die Anerkennung der Möglichkeit des Schuldig-Werdens. Mit der Behauptung der Freiheit zum Bösen (wie zum Guten) wird aber zugleich auf die Möglichkeit, die Macht dieses Bösen zu brechen oder zumindest zu schwächen, gesetzt, theologisch gesprochen: auf die Möglichkeit der Umkehr, die mit freier Übernahme von Verantwortung zu tun hat und in der Sphäre des Glaubens in den soteriologischen Kontext von Vergebung, Gnade und Erlösung gerückt ist. Mit anderen Worten: In die Diskussion des Bösen kommt also gerade dann eine religiöse Dimension, wenn sie mit Blick auf die Hoffnung oder Verheißung eines Endes des Bösen geführt wird.23

19 Dem Vorwurf von K. H. Bohrer, daß ein Werk „als Kunstwerk zerstört“ würde, sobald es erst "an philosophische oder theologische Systeme angepaßt", d. h. von deren Warte aus beleuchtet würde (Permanente Theodizee (Anm. 5, 275), wird man schwerlich folgen können.

20 W. Kasper, "Das theologische Problem des Bösen“, in: ders./K. Lehmann. (Hg.), Teufel - Dämonen - Besessenheit. Zur Wirklichkeit des Bösen, Mainz 1978, 41-69, hier 46.

21 P. Ricoeur, "Schuld, Ethik und Religion“, in: Concilium 6 (1970) 384-393, hier 389.

22 Für eine eingehende und lesbare Reflexion auf das Problem der Freiheit im Rahmen einer christlichen Antwort auf das Böse vgl:: P. Vardy, The Puzzle of Evil, London 1992. - Vardy reagiert v. a. auf die Beiträge in: M. M. Adams/R. M. Adams ( $\mathrm{Hg}$.), The Problem of Evil. Oxford Readings in Philosophy, Oxford 1990 - eine gute Einführung (mit Bibliographie) in den gegenwärtigen Stand der Diskussion im Bereich der analytischen Religionsphilosophie.

23 Vgl. P. Ricoeur, Schuld, Ethik und Religion (Anm. 21), 390-393. 
Unser Interesse soll deshalb besonders jenen Filmen gelten, in denen der Horizont der Überwindung des Bösen nicht völlig abgeblendet und der Mensch nicht ganz aus der Beanspruchung durch die Freiheit entlassen wird. Nur einige Werke können in dem folgenden Querschnitt durch das Filmschaffen der letzten Dekade eingehender diskutiert werden; bei den meisten Titeln müssen wir uns mit wenigen Strichen begnügen. Dabei wird sich auch die inhaltsanalytische Reflexion vor die Frage nach einer spezifischen Ästhetik des Bösen ${ }^{24}$ im Film schieben, obgleich die Korrelation von Inhalt und Form natürlich stets im Blick ist.

\section{Der Manichäismus des Mainstream-Kinos}

Wer sich mehr in den ,klassischen' Traditionen unserer Religions- und Kulturgeschichte als im Filmtheater zu Hause fühlt und nun womöglich erstmals die ,moralische Anstalt' Kino betritt, um sich über das Wesen und Unwesen des Bösen in ihr kundig zu machen, der wird seinen Weg wohl über die einladend breite Treppe nehmen, die zur Hauptabteilung ,Mainstream' führt, und alsbald mit Erstaunen feststellen, wie wenig hier - und damit wohl auch in dem populären Bewußtsein, das sich in ihr spiegelt - von jener Achse ,Freiheit' zu spüren ist, die erwartungsgemäß eigentlich die Grund-Koordinate des christlich inspirierten abendländischen Denkens in Sachen ,Böses' sein müßte. Stattdessen behaupten sich gerade im Bereich der ,Blockbuster', der großen Publikumserfolge, hartnäckig jene Erklärungsmuster, die ,intellektuell' schon lange überholt geglaubt waren, wenn nicht gar von Anfang an als mit dem christlichen Bekenntnis unvereinbar abgewiesen wurden. Nicht nur mit Blick auf das Böse sieht es so aus, als wären alle Denkmodelle, die geistesgeschichtlich einander abgelöst haben, im Kino plötzlich allesamt wieder in bunter Gleichzeitgkeit nebeneinander präsent, als wäre hier die diachrone ,Phylogenese' des Denkens in eine synchrone Palette zusammengestaucht.

Besonders signifikant im Mainstream-Kino ist die starke Präsenz dualistischer Interpretationen des Bösen. In ihnen tradiert sich viel an gnostischem Gedanken- und Symbolgut, wie es heute allenthalben, und zwar längst nicht nur in den populistischen Verdünnungen des Esoterik-Markts, wieder an der Oberfläche des zeitgenössischen Denkens auftaucht. ${ }^{25}$ Zahllos sind immer noch die populären Kinogeschichten, die in einem oftmals recht simplen Manichäismus und in zumeist

24 Der Band „Die Ästhetik des Bösen im Film. Materialien und Filme zum Thema" (Frankfurt/M. 1987; Amoldshainer Filmgespräche Bd. 4) steuert dazu einige interessante Facetten bei, ohne allerdings den Fragenkreis systematischer anzugehen.

25 Vgl. P. Sloterdijks großangelegten Versuch einer Rehabilitation der Gnosis, u. a. in: ders./Th. Macho (Hg.), Weltrevolutionen der Seele. Eine Lese- und Arbeitsbuch der Gnosis, Zürich 1993. 
auch ästhetisch und dramaturgisch arg ausgetretenen Pfaden die externalisierten Mächte des Bösen gegen die Heroen des Guten antreten lassen. Ob in Western oder Eastern, in Fantasy oder Science-Fiction, in Actionthriller oder Horrorfilm: was wäre die Leinwand ohne die ewigen, archetypisch-mythischen Kämpfe zwischen Gut und Böse, die auf ihr toben? Nachdem sich die Darstellungen dabei in schöner Regelmäßigkeit des reichen Fundus eines ausgebauten Symbolsystems, narrativer Konfigurationen und mythologischer Strukturen des Bösen von primär religiöser Herkunft ${ }^{26}$ bedienen, sind sie, ungeachtet der oft in kräftigen Farben aufgetragenen ,säkularen' Übermalungen, fast durchweg religiös grundiert. Allein deshalb widerspricht das populäre Kino dem Versuch, die "Renaissance des Bösen" in einem quasi religionsfreien Raum rekonstruieren zu wollen. Die großen Kinoerfolge sind der augenfällige Beweis dafür, daß jene schief liegen, die mit souveräner Geste behaupten: „Das Böse ist also wieder da ... Aber nicht als Bedrohung der Tugend oder des Guten - deren Begriffe ohnehin entleert sind - zeigt sich uns das Böse, auch nicht als Sünde, als Schuld oder Verdammnis, sondern als Gegenmacht, als der große Gegenspieler unserer von Sinn und Gott gesäuberten Wirklichkeit" ${ }^{27}$

Nicht nur daß in den filmischen Transfigurationen des Bösen die Kontinuität speziell des christlichen Bildvorrats transparent wird; dem religiösen Erbe des Abendlandes wird auch insofern Rechnung getragen, als im Mainstream-Kino, unbeschadet aller dualistischen Momente und temporären Triumphe der vielgestaltigen ,Mächte des Bösen', am Ende fast immer das Gute obsiegt und damit das Böse als das letztlich doch unterlegene Prinzip (oder,Wesen') qualifiziert wird - analog eben zur christlichen Verortung des Teufels und der Dämonen auf der Seite der Geschöpfe.

Innerhalb des breiten Repertoires der (individuell oder kollektiv) externalisierten Kräfte des Bösen, mit denen im dualistischen Modus dann das ebenfalls mit einzelnen Figuren, Gruppen oder Gesellschaften identifizierte Gute im Streit liegt, sind nach der Blüte des Okkultfilms in den 70er und frühen 80er Jahren die pluriformen Gestaltungen und Inkarnationen des Teufels und dämonischer Wesenheiten seit einiger Zeit im Abschwung begriffen, deshalb aber noch keineswegs vom Aussterben bedroht. Die Verabschiedung des Teufels seitens einer sich als ,aufgeklärt' verstehenden Theologie 28 , die schon vor einiger Zeit das "Ende des dämonologischen Zeitalters" 29 ausgerufen hat, wird offen-

26 Vgl. neben den einschlägigen Symbollexika auch P. Ricoeur (Anm. 16): J. Navone, "Das Böse und seine Symbole“, in: Concilium 10 (1974) 106-113.

27 A. Schuller/W. von Rahden, "Vorwort", in: dies. (Hg.), Die andere Kraft (Anm. 8) VII-VIII, hier VIII.

28 Z. B. in den Arbeiten von H. Haag: Abschied vom Teufel, Einsiedeln 1969; Teufelsglaube, Tübingen 1974; Vor dem Bösen ratlos?, München 1978.

29 B. Lang, Art. "Engel/Teufel", in: P. Eicher (Hg.), Neues Handbuch Theologischer Grundbegriffe, Bd. 1, München 1984, 221-230, 228. 
sichtlich von der Volksreligiosität, wie sie sich heute - oftmals hinter Masken des Profanen - nicht zuletzt im mythischen Erzählraum Kino artikuliert, nicht mitgetragen. Besonders weil sie immer wieder ihr Gesicht zu wechseln vermögen, haben Teufel und Dämonen in den Künsten noch alle Zeiten überdauert ${ }^{30}$ : So mutiert in den 80er Jahren im Kino der Pferdefuß zum Pferdeschwanz (bei der Figur des "Lou Cypher" in Alan Parkers "Angel Heart", 1986), die Schlange im Garten Eden verwandelt sich in einen geschmeidigen Sado-Maso-Leder-Mann (in Derek Jarmans "The Garden", 1990), in der - wie der Erz-Böse selbst - anscheinend unsterblichen "Omen"-Serie tarnt sich der Antichrist als Kind, zuletzt auch - wie schon in Martin Scorseses "Die Letzte Versuchung Christi" - als Mädchen ("Omen IV", 1990), oder er maskiert sich in der ihm eigenen Perfidität als Clown (Stephen Kings "Es", 1990). Demgegenüber machen sich der ,klassische $t$ Teufel/Dämon und die ihm zugeordneten (adorierenden oder exorzistischen) Riten derzeit auf der Leinwand rar. Das "Fantasy"-Genre, das mit seinen Raubzügen in die mittelalterliche lkonographie der ideale Nährboden gewesen wäre, hat sich schnell totgelaufen. In Erinnerung bleiben wird hier wohl einzig der glutrote, gehörnte Teufel, der in Ridley Scotts "Legende" (1985) im archetypisch-kosmologischen Kampf der (immerhin noch vom 2. Vaticanum angeführten) „Mächte der Finsternis" 31 gegen die Mächte des Guten unterliegt.

Als dauerhafter, nicht nur im Kino, erweist sich dagegen der Reiz des Okkulten, schwingt doch das Zeitgeist-Pendel weg von der technischen Zivilisation, von der Hyper-Rationalität des ComputerZeitalters in Richtung des Archaischen und Animistischen bzw. hin zu einer paradoxen Koexistenz der Antipoden. ${ }^{32}$ Bedeutsamere unter den zahlreichen Filmen, die beispielsweise dem Voodoo-Zauber ,huldigen', sind "Angel Heart" und John Schlesingers "Das Ritual“ (1986). Den Teufel selbst hat man zuletzt wieder gerne in die Komödie verwiesen, dorthin, wo ihm schon in den Kindertagen des Films der KintoppZauberer Georges Méliès Asyl gewährte: Als armseliger, übertölpelter Seelenfänger auf dem "Highway 61" (Bruce McDonald, 1991) erweckt er fast Mitleid, und auch gegen die "Hexen von Eastwick" (George Miller, 1986) hat er einen schweren Stand, ganz abgesehen davon, daß seine Macht mit der Rolle des potenten Lüstlings ohnehin schon depotenziert

$30 \mathrm{Zu}$ den filmischen Gestaltungen des Dämonischen in den 60er und 70er Jahren vgl. J. R. May, „The Demonic in American Cinema“, in: ders./M. Bird (Hg.), Religion in Film, Knoxville 1982, 79-100. - Für den Bereich der Literatur z. B. H. Flügel, „Begegnungen mit dem Bösen in der neueren Literatur“, in: ders./H.-M. Barth/R. Riess, Der emanzipierte Teufel. Literarisches, Psychologisches, Theologisches zur Deutung des Bösen, München 1974, 13-46; E. Osterkamp, Lucifer. Stationen eines Motivs, Berlin 1979.

31 Gaudium et Spes, Nr.37

32 Vgl. auch die Faszination für das Okkulte in der Drogenszene, wie sie Paul Schrader in seinem letzten Film "Light Sleeper" (1992) thematisiert hat. 
ist. Auch in seinen vielen Denominationen in Gestalt von Erzschurken (e.g. als "Joker" in den "Batman"-Filmen), Tierbestien, Poltergeistern und Halbwesen wie Zombies, Vampiren und Werwölfen hat der Teufel als Inkarnation des Bösen viel von seinem Schrecken verloren. - Freilich sollte man vorsichtig sein und der Teufelsfigur angesichts ihres aktuellen Niedergangs, ihres Abdriftens ins epigonale Remake und ins Spiel mit Selbst-Zitaten, nicht gleich das Todeszeugnis ausstellen. Der Teufel hat es prächtig überlebt, daß vor bald 150 Jahren Karl Rosenkranz befand, er sei "für die Kunst überflüssig geworden." ${ }^{33}$ Mag auch die Personifikation des Bösen in Gestalt des Teufels ein Fall von "anachronistischer Symbolik" (Käte Hamburger) ${ }^{34}$ und der Rekurs auf das "konventionelle satanische Paradigma" ein Beitrag zur Konservierung der herkömmlichen Theodizee sein ${ }^{35}$ - man wird dennoch mit dem Faktum leben müssen, daß sich die Teufelsvorstellung bislang gegen alle ideologiekritischen Demontagen resistent gezeigt hat, ja vielleicht schon wieder vor einer neuen Blüte steht. ${ }^{36}$ Das kommt wohl vor allem daher, weil sich in ihr der Hang $\mathrm{zu}$ einer dualistischen Betrachtung des Bösen verdichtet, welche immer schon dadurch attraktiv war, daß sie den Einzelnen ein gutes Stück weit vom Anspruch, der aus der Behauptung der Freiheit entspringt, entbindet, indem Schuld und Verantwortung auf einen anderen, eben den Versucher, abgeladen werden.

\section{Wachsende Ambivalenzen}

Der alte Dualismus von Gut und Böse und die ihm zugehörige Symbolik - etwa der Farben (hell vs. dunkel), des Raumes (oben vs. unten), des Kämpfens (fair vs. hinterrücks) oder auch des Mahlhaltens (speisen vs. fressen) - regieren also nach wie vor die populären Genres. Je mehr sich das Böse dabei von der Figur des Teufels (etc.) ablöst, desto bedrohlicher wird es, desto hartnäckiger widersetzt es sich seiner ,Nichtung' durch das Gute. Und schlimmer noch: wo früher - wie idealtypisch in Don Coscarellis B-Picture "Phantasm" (1977) ablesbar das Böse klar lokalisiert war, im couragierten Kampf von denen mit ,reinem Herzen' besiegt und zurück in den Orkus gejagt werden konnte, aus dem es hervorgekrochen war; wo früher, in den für manche inzwischen schon wieder ,seligen' Zeiten des ,Gleichgewichts des Schreckens', noch der Amerikaner das Gute und der Russe das Böse verkörpern konnte ("Rocky IV", 1985), da wird heute die saubere Grenzziehung zwischen Gut und Böse immer brüchiger.

33 K. Rosenkranz, Ästhetik des Häßlichen, Leipzig 1990 (Erstausgabe: 1853), 307.

34 Zit. n. K. H. Bohrer, Permanente Theodizee (Anm. 5), 280.

35 Ebd., 281.

36 Vgl. T. Peters, "The Selling of Satan in Popular Literature", in: Christian Century 108 (1991) 458-462. 
Wachsen die Interferenzen und Ambivalenzen, gerät die stets im Hintergrund präsente Erlösungssehnsucht in eine immer tiefere Orientierungskrise. Im Science-Fiction-Film etwa, der das Böse im Modus des Kosmischen und Technischen in einer der Welterfahrung und projektiven Imagination der modernen Industriekultur besonders akkommodierten Form präsentiert, sind die Zeiten der märchenhaft klar geordneten "Star Wars"-Serie dahin. Die Monstren, die seither in der Zukunft lauern, werden zusehends schrecklicher und zerstörungsresistenter (z. B. in der "Alien“-Trilogie. 1979-92), immer täuschendere Replikanten und perfektere Maschinenmenschen paralysieren die Konturen der Schöpfungsordnung. Der Sieg des Guten wird immer folgenloser, ändert immer weniger an der globalen Unheilssituation: mögen auch punktuelle Ausbrüche gelingen, das Los Angeles des "Blade Runner" (1982) ist am Ende derselbe apokalyptische Moloch wie zu Beginn. Die beiden "Terminator"-Filme $(1984,1992)$ dagegen belehren ihr Publikum darüber, wie Gut und Böse die Seite wechseln können, wie Gewalt unter verändertem Vorzeichen - und in ihrer Zerstörungskapazität unter dem letalen Level zurückgenommen plötzlich zum Heilswerkzeug geraten kann: Im massiv religiös getönten "Terminator II" ist die Kampfmaschine "Schwarzenegger' von der Inkarnation des seelenlos wütenden Bösen zum "Christopherus" mutiert, der ein neues messianisches Kind durch die Höllengluten, die es verzehren wollen, trägt. ${ }^{37}$

Immerhin bleiben hier aber doch noch Gut und Böse, Schuld und Unschuld einigermaßen sauber geschieden, was freilich auch notwendig ist, damit die action-hungrigen Kids in dem allgemeinen Gemetzel einigermaßen den Überblick behalten. Dieser Optimismus der Unterscheidung ist jedoch in anderen populären Genres schon lange am Bröckeln. Neuere Prototypen für den Bereich von Mafia-Thriller und Western sind hier Abel Ferraras "King of New York" (1990) und Clint Eastwoods "Erbarmungslos“ (1992). Beide Filme sind weniger wegen ihrer exzessiven Gewaltszenen bedrängend - in dieser Hinsicht hat man mittlerweile schon einiges ertragen lernen müssen -, sondern in erster Linie, weil sich in ihnen Schuld und Unschuld vermengen und so der Zuschauer nicht aus dem unbequemen, weil immer schwierigen moralischen Urteilen entlassen wird.

In Frank White, dem "King of New York", dessen Weg an die Spitze der Drogenmafia mit Leichen gepflastert ist, zeigt Ferrara nicht einfach einen menschenverachtenden, egomanischen Killer, sondern eine bei aller Härte zugleich sehr empfindsame Figur, der keineswegs alle moralischen Maßstäbe abhanden gekommen sind: Von einer langen

37 Die Deutung als Christopherus verdanke ich P. Sloterdijk, "Sendboten der Gewalt. Der Mensch als Werfer und Schütze - zur Metaphysik des Action-Kinos", in: Die Zeit, Nr.18 v. 30.4.1993, 57-58, 58. 
Haftstrafe gezeichnet und in einem Leben unter permanenter Todesdrohung ständig mit der Endlichkeit seines Daseins konfrontiert, richtet sich eines Tages Franks ganzes Sinnen und Trachten darauf, die zur Erhaltung eines Harlemer Kinderkrankenhauses nötigen Millionenbeträge zu beschaffen. Ferrara: „Frank White ist jemand, der fest daran glaubt, die Dinge verändern zu können. Er als Individuum hat seine Vision und weiß, er kann sie verwirklichen. Er glaubt noch immer daran, daß das Leben etwas wert ist, obwohl er kein Heiliger ist." Er "hat sein halbes Leben im Gefängnis verbracht und wuchs in einer so grauenhaften Realität auf, daß er wenigstens einmal etwas ,Gutes' tun will."38 Doch Franks Vorhaben ist von vorneherein zum Scheitern verurteilt: nicht nur, weil das Gute durch Böses kommen soll, sondern auch weil er sich mit seinem humanitären Impuls in seiner Umgebung isoliert. Als er am Ende in einem von der Polizei umstellten Taxi an einer Schußverletzung stirbt, ist dies ein einsamer, müder, resignierter Tod: weniger eine ,Strafe' als - ähnlich wie beim Tod von Pasolinis "Accattone" (1961) - eine Befreiung aus dem irdischen ,Tal der Tränen', in welchem das rauschhaft-fiebrige, von einem Grundgefühl des ,carpe diem' aufgepeitschte Taumeln zwischen Gewalt, Sex und Drogen ein letztlich verzweifeltes Surrogat des wahren Lebens war.

Deshalb will man Frank, bei aller Schuld, die er auf sein Haupt geladen hat, doch nicht endgültig aus der göttlichen Gnade herausfallen sehen. - Noch bedrückender wird das Ineinander von verschütteter, aber immer wieder aufblitzender Menschlichkeit (und hier auch explizit religiöser Empfindung) und exzessiver Gewalttätigkeit in der Figur des am Ende von seinem eigenen Kains-Bruder erschossenen Drogendealers Jackie in Phil Joanous "Im Vorhof der Hölle" (1990; Original-Titel: State of Grace). Die Antwort, die Joanous Geschichte auf die dem Titel implizite Frage nach dem Zustand der Gnade gibt, ist ein einziger großer Klageschrei. Aber selbst die Klage ,de profundis' kann ja eine Form des Gebets sein, zumal wenn sie, wie hier, aus einer Geschichte mit ausgeprägt moralisch-religiöser Tiefenstruktur aufsteigt.

Auch der Moral des Western, die einmal "die Moral einer Welt" war, "in der Gut und Böse unvermischt nebeneinanderstehen wie zwei einfache Grundbegriffe" 39 , sind ihre klaren Konturen abhanden gekommen; die alten "Ritter für die gerechte Sache" 40 werden von ambivalenten Figuren verdrängt: Der ,Held' in Eastwoods "Erbarmungslos" ist der von ihm selbst dargestellte ehemalige Revolverheld Bill Munny, der früher bisweilen völlig grundlos getötet hatte bzw. sich zumindest rückblickend an kein Motiv erinnern kann, weil er ständig betrunken

38 Zit. n. Th. Gaschler/E. Vollmar (Hg.), Dark Stars. 10 Regisseure im Gespräch, München 1992, 61/62.

39 A. Bazin, Was ist Kino? Bausteine zur Theorie des Films, Köln 1975, 118.

40 Ebd., 116. 
war. Durch die Liebe einer Frau wurde er aus dem Strudel des Bösen herausgerissen, fristet jetzt aber mit seinen Kindern ein zwar ehrliches, aber erbärmliches Leben als Schweinezüchter. Als solcher ist er ,ganz unten', wortwörtlich bis zum Hals im Dreck - und man entsinnt sich hier vielleicht des Motivs des schweinehütenden, verlorenen Sohnes'. Doch selbst Erniedrigung und materielle Not rechtfertigen es nicht, daß er sich wieder als Kopfgeldjäger anwerben läßt. Daß der Auftrag darin besteht, die Verstümmelung einer Frau zu rächen, ist letztlich nur der willkommene moralische Vorwand zur Beruhigung von Bills Gewissen. (Das Gewissen meldet sich etwa darin, daß er die Erzählung von den Verletzungen der Frau immer drastischer ausmalt.) Die Erledigung des ,Jobs ${ }^{t}$ gerät $\mathrm{zu}$ einem entsetzlichen Abschlachten, das auch die drei Killer in ihrem Innersten trifft und ihre einander vorgetäuschte Kaltblütigkeit aufsprengt. Als der eigentlich Böse entpuppt sich der Sheriff ,Little Bill' - die Namen haben im Kontext des Western-Mythos allesamt die Aura des Archetypischen -, der in der Maske des Biedermanns und Gesetzteshüters das ,Recht' ${ }^{\prime}$ zu verteidigen vorgibt, in Wahrheit aber vor allem seine sadistischen Triebe ausagiert. Nachdem er Munnys Gefährten Nat zu Tode gefoltert hat, wird er im Showdown von Munny erschossen. Die letzten Worte, die der Sheriff dem wie ein unverwundbarer und unbarmherziger Engel der Vergeltung arbeitenden Munny entgegenschleudert, sind ein: "Wir sehen uns in der Hölle!“ Obwohl der andere dies bejaht - und das angesichts der vielen Morde, derer er sich schuldig gemacht hat, sicher nicht ohne Grund -, sträubt sich der Zuschauer gegen diese Selbstverdammung, mit der Munny meint, dem göttlichen Richterspruch zuvorkommen zu können. Denn in seinen Gewissensregungen, in seinem Schmerz und Mitgefühl war sichtbar geworden, daß die Macht des Bösen über ihn eigentlich gebrochen ist.

Mit ambivalenten Protagonisten wie Frank White und Bill Munny sind die alten, in den populären Genres so beliebten dualistischen Muster verlassen. Obgleich bei Ferrara und Eastwood nach wie vor auch Figuren auftreten, die recht eindimensionale Verkörperungen (vor allem) des Bösen sind, vermengen sich doch zumindest in den "Helden' gute und böse Anteile dergestalt, daß der Zuschauer in seinem Identifikationsbedürfnis verunsichert wird. Ablehnung und Sympathie ringen miteinander. Welches Gefühl die Oberhand behält, hängt nicht zuletzt davon ab, wie die Antwort auf die Frage nach dem Spielraum ausfällt, den die ,gemischten' Charaktere haben, um die bösen Anteile zugunsten des Guten zu verändern, wie weit ihre Kraft und Freiheit reicht.

Ein erfolgreiches CEuvre, das sich von Anfang an in besonderer Weise eben dieser Problematik angenommen und gegen simplifizierende Dualismen in Sachen Gut und Böse gesträubt hat, ist das Filmschaffen von Martin Scorsese. Im Bereich des populären Films hält es wohl mit die eindringlichsten Beispiele für religiös transparente Thematisierungen von Gewalt und Gnade, Vergeltung und Vergebung, 
Schuld und Erlösung bereit. Was Scorsese einmal mit Blick auf den Box-Champion Jake La Motta, dem er in der Passionsgeschichte "Raging Bull“ (1980) ein Denkmal gesetzt hat, sagt, das verbindet ihn mit vielen seiner Figuren: "das katholische Erbe, das Gefühl der Schuld, die Hoffnung auf Erlösung." " ${ }^{11}$ Besonders in den verschiedenen Figurationen des ,Schwarzen Engels', die Scorseses Filme durchziehen ${ }^{42}$, gewinnt die "unaufhebbare Gleichzeitigkeit von Gut und Böse" 43 , d. h. daß "das Gute das Böse und das Böse das Gute nicht ausschließt" ${ }^{44}$, Gestalt. Diese Spannung wird ja gerade im christlichen Glauben durchgehalten und begründet hier, insofern sie nicht aus menschlicher Kraft allein endgültig überwunden werden kann, die Erlösungsbedürftigkeit des Menschen.

Scorseses Verteidigung der Ambivalenz gegen moralisierende Schwarz-Weiß-Malerei läßt sich sehr gut an seinem Remake "Cape Fear" (1991) studieren. Er verläßt hier die moralisch einfache Kontrastierung von ,unschuldig Verfolgtem' und 'bösem Verfolger', indem er gegenüber der Vorlage ein Schuldmoment - die Zurückhaltung eines sicher strafmildernden Gutachtens - in der Vergangenheit des äußerlich integren Anwalts Sam Bowden etabliert, was zugleich den Vergeltungswahn seines Ex-Klienten Max Cady ein Stück weit nachvollziehbar macht. Durch diese Änderung in der Ausgangskonstellation gewinnt das Geschehen einen komplexen Subtext hinzu,-der die Unterscheidung von Gut und Böse in die Spannung von (ewigem) moralischem Gesetz und weltlicher Rechtsordnung stellt und die Handlungsrelevanz des Gewissens erkundet: denn mit dem Zurückhalten von Entlastungsmaterial macht sich Sam Bowden einerseits vor der Strafprozeßordnung und seiner Standes-Ethik schuldig, andererseits bleibt er aber so der Stimme seines Gewissens treu, die ihm angesichts der evidenten Zurichtung des Opfers von Cady die anwaltliche Mithilfe an einem möglichen Freispruch verbietet. (In der Warnung an Max, mit der Sam später einen schuldhaften Selbstjustiz-Versuch im letzten Moment nochmals korrigieren zu können hofft, meldet sich sein Gewissen erneut.) Insofern bleibt Sam auf dem Boden der christlichen Moral, die das Gewissen als letztverpflichtende Instanz kennt, andererseits - und das ist eben die Ambivalenz - macht er sich doch auch in den Koordinaten dieser Ethik schuldig, weil er sich, statt den Fall abzugeben, indirekt selbst zum Richter aufschwingt und meint, der göttlichen Gerechtigkeit zuvorkommen bzw. ,auf die Sprünge helfen' zu müssen. Dieser Zug verbindet ihn mit Max Cady, nur daß bei diesem die Gewichte von Schuld und

41 Zit. n. H. D. Rusche, „Die Bürde der Tradition“, in: P. W. Jansen/W. Schütte (Hg.), Martin Scorsese, München 1986 (Reihe Film 17), 7-30, hier 26.

42 Vgl. den anregenden Essay von P.W.Jansen, "Schwarze Engel“, in: ebd., 31-52.

43 H. W. Dannowski, "Scorsese/Schrader“, in: epd Film 4 (1987) Nr. 11, 2-5, hier 2.

44 Ebd. 
Unschuld vertauscht sind. Anfangs, als er sich aufmacht, für das ihm (in seinen Augen und in der Optik des weltlichen Gesetzes) widerfahrene Unrecht Vergeltung zu suchen, wird der Zuschauer Max ein gewisses Verständnis nicht versagen. Durch die vielen, vornehmlich alttestamentlichen Bibelzitate, die er nicht bloß im Mund führt, sondern als unauslöschliche Handlungsmaximen seinem Körper eingeschrieben hat, durch die Bibel, die in einer der Waagschalen des großen Gerechtigkeits-Emblems liegt, das er seinem Rücken hat eintätowieren lassen, reklamiert Max für seinen zur Gerechtigkeits-Arbeit stilisierten Rachefeldzug die göttliche Legitimation. Dabei unterschlägt er freilich nicht nur geflissentlich alles, was die Bibel von Vergebung, Feindesliebe und Gewaltlosigkeit weiß, sondern identifiziert sich einmal überheblich mit Nietzsches über jede Moral erhabenen ,Übermenschen', dann wieder maßt er sich an, ein von Gott auserwählter Racheengel und schließlich Gott selbst zu sein. Doch nicht nur in diesem "wie Gott sein wollen" wiederholt sich der erste Sündenfall; die Urgeschichte ist u.a. auch bei der ,Versuchungsszene' konnotiert, als Max, ganz mephistotelischer Verführer, die Tochter Sams umgarnt. Mit seinen zunehmend diabolischen Zügen mutiert Max immer mehr zur Luzifer-Gestalt, deren Sturz sich schließlich in seinem Untergang wiederholt.

Die allmähliche Freilegung des Teufels in Max Cady könnte nun die eingangs $c^{2}$ ablierte ethische Komplexität in Richtung Dualismus einebnen, wüchsen parallel dazu nicht die mysteriösen Momente, die in das Geschehen nochmals eine interessante Brechung bringen. Angefangen mit Max' urplötzlichen Auftauen und Verschwinden, mit seiner kontinuierlich sich steigernden ominösen Omnipräsenz im Leben des Anwalts, über den geheimnisvollen Tod von Sams Hund, das unerklärliche Verschwinden von Saiten aus dem Klavier in Sams Haus, bis hin zur Feuerresistenz Cadys im Showdown: das Wesen dieses ,Bösen' wird immer unerklärlicher. Diese Entwicklung kulminiert in jener Szene des Finales, in der Sam Max' Blut von seinen Händen waschen will und diese plötzlich so rein sind, als hätte nie ein Kampf stattgefunden. Damit wird nun vom Ende her denkbar, daß alles, was zuvor geschehen ist, eine Phantasmagorie, eine Reise durch das Schattenreich von Sams Seele war, daß ,Max' - der Aussprache nach nicht weit von einem rückwärtsgesprochenen ,Sam' entfernt - womöglich der personifizierte Schuldkumplex in Sam ist, der als ein unbewältigter immer mächtiger nach außen drängt, bis er in einem Kampf auf Leben und Tod besiegt wird, in einem Ringen, das symbolträchtig stattfindet auf einem reißenden, irreal aufgewühlten Strudel, der das Seelen-Schifflein zum Kentern bringt. Das Leben, zu dem Sam und seine Familie am Ende aus den urgewaltigen Fluten (wieder-)geboren werden, lehmgestaltig wie die Menschen des zweiten Schöpfungsberichts, ist von diesem Kampf gezeichnet. Die Unschuld ist endgültig verloren. 


\section{Das Böse in den Abgründen der Seele}

Folgt man diesem Interpretationsversuch von Max Cady als Personifikation der ,dunklen' Anteile im Unbewußten Sams, dann zählte "Cape Fear" bereits zu jenen Filmen, die das Böse bevorzugt in den Tiefen des Unbewußten, als den Abgrund, der in jedem lauert, freizulegen suchen. Derartige Reisen in die sinistren Regionen der Psyche gibt es im Kino schon lange, man denke nur an Georg Wilhelm Pabsts "Geheimnisse einer Seele" (1925) oder an die klassischen Bette Davis-Thriller; und programmatisch starb ja schon Orson Welles' "Lady von Shanghai" (1946) mit den Worten: "Das Böse ist in mir". ${ }^{45}$ - Doch es sieht so aus, daß die Reisen in die Dunkelzonen in den letzten Jahren an Ausweglosigkeit und Schrecklichkeit, gleichzeitig aber auch an Popularität um einiges zugelegt haben.

Damit scheint das Kino auf die wachsende „neue Unübersichtlichkeit" (Jürgen Habermas) unserer Wirklichkeit und das zunehmende Gefühl der elementaren Verunsicherung, die sie hinterläßt, zu reagieren: Nach der Lesart seiner Apologeten bindet dieses Kino des neuen Schreckens das numinose Unbehagen und hilft die alltäglichen Unheilserfahrungen bewältigen, indem es aufgestaute Ängste kathartisch freisetzt. In einer Situation, in der dem Zuschauer in der Realität mehr und mehr der Boden unter den Füßen entgleitet, und es für ihn immer schwieriger wird, richtig und falsch, gut und böse zu unterscheiden, erscheinen die alten, einfachen Dualismen mehr und mehr wie nostalgische Relikte einer geordnet geglaubten Wirklichkeit. Man rettet sich zwar noch gerne für eine Weile in sie - daher ihr ungebrochener Erfolg -, doch gleichzeitig weiß man um ihre Defizienz, weiß, daß die eigentliche Bedrohung durch das Böse aus dem Innern des Menschen, und zwar letztlich eines jeden Menschen kommt. Indem Filme dies thematisieren, stellen sie natürlich (zumindest implizit) immer auch die Frage nach der Freiheit zum Bösen bzw. der Möglichkeit, ihm aus freiem Willen zu widerstehen. Mit Blick darauf wird zu sehen sein, ob das Böse dabei gänzlich in den Regelkreisen einer Triebmechanik aufgeht und das Kino zum (epigonalen) Erbhalter einer in ihrem Totalerklärungsanspruch schon längst erschütterten Psychoanalyse gerät, oder ob doch so viel an Freiheit des Willens präsent bleibt, daß die Hoffnung auf ein Entkommen aus der Dynamik des Bösen nicht ganz erlischt und ein religiöser Horizont offengehalten wird.

In vielen Fällen sieht es nun tatsächlich so aus, daß die Dimension des Bösen ausschließlich mit Hilfe psychologischer und milieutheoretischer Optiken vermessen werden soll, und dieses Böse, wenn es erst aus dem religiösen Zusammenhang von Freiheit, Schuld und Erlösung

45 Vgl. F. Donovan, „Le Mal au Cinéma“, in: Cinéma (Paris) (1989) Nr. 459, 3-4, hier 4. 
herausgenommen ist, am Ende zu einem bloßen ,Defekt' gerät. Was daran deprimierend ist, darüber läßt der österreichische Regisseur Paulus Manker den Philosphen Otto Weininger in einem langen imaginären Dialog mit Sigmund Freud Klage führen: daß durch die psychologische Verrechnung von Verantwortung und Schuld die Möglichkeit von Reue und Umkehr hinfällig und so Hoffnung demontiert wird ("Weiningers Nacht", 1989).

Nicht selten wird verdeckt, daß der Blick in die Abgründe der Seele dem Geist der neuzeitlichen Religionskritik verpflichtet ist. Nachdem selbst bei säkularer Fokussierung gerne mit den Gedankenund Bildarsenalen religiöser Denomination gespielt wird, erhalten viele Filme an der Oberfläche einen (pseudo-)religiösen, (pseudo-)mythischen Anstrich, wie er zur Zeit kommerziell erfolgreich ist. Natürlich macht man sich auch klassische Motive anderer Herkunft zunutze, um dem Numinosen des Bösen sichtbare Gestalt zu verleihen. Besonders beliebt ist dabei das - eben bereits bei Scorsese vermutete, dort aber anders kontextuierte - Motiv der nach außen verlegten Personifizierung der ,dunklen Seite' des Menschen, seines ,Schattens', in Gestalt einer bösen Gegenspieler- oder Doppelgänger-Figur, wie z.B. in Alan Parkers "Angel Heart", einem Film, der eine raffinierte neue Variante des alten Motivs der Persönlichkeitsspaltung à la "Dr. Jekyll and Mr. Hyde' vorlegt, mit dem im Kino46 und in der Literatur schon so oft die Dialektik von Gut und Böse zu fassen gesucht wurde.

Wie Parker arbeitet auch Jonathan Demme in "Das Schweigen der Lämmer" (1990) mit einer Vielzahl von religiösen Motiven und Anspielungen: Eine durch die Tötung unschuldiger Lämmer (sic!) traumatisierte FBI-Agentin tritt an gegen einen noch in seiner Verworfenheit charismatischen Teufel in Menschengestalt, den hyperintelligenten Ex-Psychiater Hannibal Lector, der quasi auf die andere Seite hinübergewechselt ist und nun als kunstsinniger Psychopath seine Opfer kreuzigt, delikat zubereitet und ,verkostet', und gegen dessen Adlatus 'Buffalo Bill', einen von der Idee der Metamorphose seines Leibes besessenen Serienmörder, einen Narziß, der sich zum Heiligen, ja zum Christus (z. B. mit einer selbst zugefügten Seitenwunde) stilisiert. Doch all der Wirbel von ikonographischen Verweisen auf die christliche Heils- und Kunstgeschichte ${ }^{47}$ vermag nicht darüber hinwegzutäuschen, daß in Demmes finsterer Welt letztlich nur wenig Platz für einen tieferen theologischen Deutungshorizont ist. Hannibal Lector und Buffalo Bill leiden nie an dem Bösen, das sie tun; Gewissen und Schuld

46 Vgl. M. Schlappner, „Das Böse und der Film“, in: Das Böse. Studien aus dem C. G. Jung-Institut Zürich XIII, Zürich-Stuttgart 1961, 127-159, hier 134.

47 Vgl. die minutiöse Analyse von H. Niewöhner, „Mythisches Perpetuum Mobile. Das Schweigen der Lämmer - der Film und seine Betrachter“, in: Lettre International (dt. Ausgabe) (1992) Nr. 19, 48-54. 
sind ihnen Fremdworte. Lector trägt allzu manische Züge, als daß er als Prototyp des "satanischen Subjekts" fungieren könnte, das durch eine "selbstbewußte, freie Hervorbringung des Bösen" charakterisiert ist.48 Eher ist er die Inkarnation der freigelassenen Bestie, die in jedem lauert, des "Raubtiers im Menschen", von dem Nietzsche sprach, die Vorhut der von diesem prognostizierten "außermoralischen Periode " ${ }^{49}$ in der sich der "Wille zur Macht" über jede moralische Bestimmung erhoben hat. Bei aller dunklen - den Zuschauer wohl nicht anders als die Agentin irritierenden - Faszination, die Lector ausstrahlt, ist er am Ende doch nur ein apotropäisches Monster, aufgerichtet anscheinend gegen das wieder populär werdende Liebäugeln mit "Übermensch“ und "Herren-Moral ${ }^{\prime}$.

Tiefer als bei Demme reicht die religiöse Kontur, die dem Oeuvre von David Lynch eingezeichnet ist, einem Werk, das von Anfang an mit besonderer Beharrlichkeit und Phantasie die "dunklen Regionen des Daseins"50 sondiert hat, den ,Schatten' (C. G. Jung) in der Seele des Menschen, den Stoff, aus dem die Alpträume gemacht sind. Wie Lynch selbst wiederholt bemerkt hat, fasziniert es ihn, „im Unterbewußten der Leute zu forschen, in diese unendliche Zone einzutauchen“. Denn: „Was die Oberflächen zeigen, ist nur ein Teil der Wahrheit. Darunter steckt das, was mich am Leben interessiert: die Dunkelheit, das Ungewisse, das Erschreckende, die Krankheiten. - In jedem meiner Filme geht es um die Oberfläche der Dinge und was sich darunter verbirgt. Kann sein, daß ich besessen bin von den verborgenen Dingen" 51 .

Notwendigerweise nimmt deshalb in Lynchs Filmen gerade auch die Erkundung des Geheimnisses des Bösen breiten Raum ein. Am deutlichsten gerät die ,Lösung' dieses Rätsels in der populären TV-Serie "Twin Peaks" (1989ff) und dem ihr nachgeschickten Spielfilm-Prolog "Twin Peaks - Fire walk with me" (1992). .22 Dabei sind die Rekurse auf die verschiedensten religiösen Traditionen unübersehbar, auch solche auf biblisch-christliche Motive: Wo etwa im Evangelium der Teufel von Judas Besitz ergreift und ihn zu seinem Werkzeug macht, wo dort von Dämonen Beherrschte zu unkontrollierbarer Gewalt neigen (vgl. Mk 5,1ff.), da ist es in "Twin Peaks" die das Böse verkörpernde Gestalt des ,Killer Bob', die sich Leland Palmers bemächtigt und ihn nicht mehr Herr seiner selbst sein läßt. Im Tod aber, unter den (in eine

48 K. Rosenkranz, Ästhetik des Häßlichen (s. O., Anm. 33), 297.

49 F. Nietzsche, Jenseits von Gut und Böse. Mit der Streitschrift "Zur Genealogie der Moral“, Frankfurt/M. 1984, 44.

50 R. Fischer, David Lynch (Anm. 1), 10.

51 Zit. n. ebd., 271.264.

52 Für eine detaillierte Analyse der Serie (allerdings ohne Einbeziehung des Spielfilm-Prologs) vgl. jetzt M. Verbeek, "It's the mystery that's the fun of life", in: Z. Cavigelli et al. (Hg.), Aus Leidenschaft zum Leben. Film und Spiritualität, Zürich 1993, 171-195. 
Sprinkleranlage verwandelten) Wassern des Gnadenstroms, vermag Leland die große Lebensbeichte abzulegen und findet sterbend seinen Frieden wieder (Folge 17). Ohne ähnlich unmittelbar von ,Bob' überwältigt zu sein, geben auch andere Bewohner der vermeintlich ,sauberen' Kleinstadt den Lockungen des Bösen nach und ertrinken in einem Mahlstrom der Gewalt und Exzesse. Selbst der FBI-Agent Cooper - und mit ihm (anscheinend) das Gute - erliegt am Ende dem Bösen. Sein als Doppelgänger personifizierter Schatten ,triumphiert', obgleich Cooper zuvor im Setzen auf das Spirituelle, in der Anerkennung anderer Kräfte als derjenigen der Vernunft, eigentlich den Schlüssel zur Überwindung ,Bobs' in Händen gehalten hätte.

Daß Lynchs Erkundung des Bösen, das „unter der idyllischen Oberfläche gärt", 53 immer wieder an die C. G. Jungschen Reisen in die Zone des kollektiven Unbewußten erinnert, liegt auch an seinen zahlreichen archetypischen Figuren und Handlungsmotiven, die aus der Märchen- und Mythenüberlieferung vertraut sind ${ }^{54}$ : Da gibt es mit der tief im Wald versteckten "Black Lodge" einen klassischen Ort des Bösen, da erscheinen Zwerg und Riese, da werden Seelen gejagt und verkauft (Folge 30). - In "Blue Velvet" (1986) und "Wild at Heart" (1990) ist es vor allem das Handlungsmuster der läuternden Reise, das den mythischen Horizont trägt: Ähnlich der Grundbewegung in "Twin Peaks" dringt Jeffrey, der ,reine' Held von "Blue Velvet", in die geheimnisvollen, nächtlichen Regionen der Stadt und damit in die dunklen, zuvor verschlossen gehaltenen Kammern seiner eigenen Seele vor. Wie aus einem "bösen Traum" - so zeichnet er es selbst - taucht er aus dieser Reise in den Untergrund innerlich verändert wieder an die lichte Oberfläche des jetzt als fragil und trügerisch erkannten Alltags, des ,kleinen Glücks', empor. Jeffrey, die Identifikationsfigur, hat dem Bösen, dem Abgründigen ins Angesicht geblickt - dem Bösen im anderen (in Frank Booth) und in seinem Innern - und hat ihm widerstanden, nicht zuletzt durch die Kraft der Liebe. So gesehen ist "Blue Velvet", unbeschadet seiner gewalttätigen Außenseite, ein veritables Märchen für Erwachsene. - Noch deutlicher wird dieses Märchenhafte dann in "Wild at Heart", wo am Ende nicht mehr bloß wie in "Blue Velvet" ein Rotkehlchen Glück verheißt - in ironischer Brechung allerdings eines aus Plastik -, sondern die gute Fee aus "The Wizard of $\mathrm{Oz}^{\prime \prime}$ dem archetypischen Liebespaar Sailor und Lula winkt, als dieses am Ende seiner ,Aventure'-Fahrt durch ein Fegefeuer der Gewalt angelangt ist.

Damit dürfte auch schon die große Gefahr von Lynchs Filmen deutlich geworden sein: daß sie ihr Thema an ein eklektizistisches Spiel

53 R. Fischer, David Lynch (Anm. 1), 235.

54 Vgl. M. L. von Franz, Der Schatten und das Böse im Märchen, München 1985. 
mit Zitaten, Motiven und Stilen verraten und ins Unverbindliche abgleiten. Dennoch sind seine Erkundungen des Bösen, bei der all die Ängste, die Pervertierungen und die Gewalt unserer Zeit luzide aufleuchten, mehr als schicke Akkommodationen an den Zeitgeist. Erstaunlich mutig stellt Lynch in und gegen diese vom Bösen durchwucherten Geschichten immer wieder Hoffnungsbilder der Gnade und Erlösung, in die, durch all den postmodernen Zierrat und plakativen Kitsch hindurch, doch eine tiefe Sehnsucht der Menschen unserer Tage einfließt. In diesen Bildern wird ihre Erlösungshoffnung aus den Fesseln eines Nihilismus befreit, der sie verächtlich als anachronistisch beiseite schieben will. Vielleicht ist es ein Zufall, vielleicht aber auch Ausdruck eines allmählichen Ungenügens des allzu Märchenhaften und des allzu schnell von Beliebigkeit bedrohten Synkretismus, daß die Erlösungsbilder in Lynchs letztem Film von ihrer Ikonographie und Symbolik her einen deutlicheren Bogen zur christliche Vorstellungswelt schlagen und bei aller Phantastik insofern auch eine Spur ,realistischer' sind, als sie Erlösung nicht mehr unbedingt auf Erden anvisieren: Am Ende von "Twin Peaks - Fire walk with me" erhebt sich die Seele des toten, zuvor vom Bösen besessenen Leland Palmer und beginnt zu schweben, wie befreit von der Schwere ihres Daseins und der Last ihrer Sünden. Als ,Bob' den Schwebenden wieder unter seine Gewalt zu zwingen sucht, prallt er zurück: seine Macht ist gebrochen. Und in einer doppelten Schutzengel-Vision wird auch die ,gefallene' ${ }^{\prime}$ Laura Palmer nach ihrem Tod wieder aufgenommen. Thr Lachen und ihre befreienden Tränen künden von ihrer Erlösung - und begleitet von Cherubinis Requiem in C-Moll rollen dann gerade über die Bilder, die dies zeigen, die Abspann-Credits. Mit diesem Ende konterkariert Lynch den pessimistischen Ausklang der vorausgegangenen Serie, den (scheinbaren) Sieg des Bösen.

Was die Filme von David Lynch oftmals so drastisch illustrieren, davon spricht nicht erst Kant in seiner Rede vom "radikal Bösen", 55 davon reden bereits die christlichen Grundformeln des Credo, des Taufbekenntnisses und des Vaterunser: von der tiefgründigen Neigung des Menschen zum Bösen als Teil der conditio humana. Der Glaube weiß den Menschen aber dieser Neigung nicht völlig ausgeliefert, sondern behauptet in einem bisweilen skandalös anmutenden ,Dennoch" seine Freiheit zum Guten und die Hoffnung auf Gnade. Vor allem als Gefühl der Erlösungsbedürftigkeit, als Sehnsucht nach Frlösung hält sich diese Hoffnung auf eine Überwindung des Bösen auch bei Lynch durch - und sei es in der Maske des spielerischen (Kitsch-)Zitats. Anders wagen heute anscheinend viele überhaupt nicht mehr von ihr zu reden.

55 I. Kant, Die Religion innerhalb der Grenzen der bloßen Vernunft, 1793. 


\section{Umkehrgeschichten}

Keine der bislang betrachteten Variationen des Bösen im populären Kino ist frei von (krypto-)religiösen Momenten und mythischen Substrukturen. Bisweilen gewinnen die Sedimente derselben auch an der Oberfläche der Handlung und der Bildwelt markantes Profil, wobei jedoch die ,ideologisch' unverfänglicheren Rekurse auf archetypischmythische Elemente die Bezugnahmen auf die christliche Tradition bei weitem überwiegen. Im Unterschied zu den zahlreichen, philosophischen' Filmen vor allem der 50er und 60er Jahre, die die Frage nach dem Bösen und der Schuldverstrickung des Menschen bis tief hinein in ihre existentiellen und religiösen Dimensionen ausgeleuchtet bzw. diese Frage in einem oft schonungslosen Insistieren auf den Aporien gängiger Antwortversuche offengehalten haben (man denke etwa an die Filme Ingmar Bergmans oder Luis Buñuels) ${ }^{56}$, wird heute im Kino zumeist der gedanklich und oft auch ästhetisch spröderen Reflexion, die ,ungeniert ${ }^{\prime}$ philosophisch-theologische Dimensionen ansteuert, ausgewichen - zugunsten der Befriedigung der Schaulust und des Nervenkitzels, zugunsten der Lust am (vermeintlich?) kathartischen Entsetzen. Trotz all des Bösen, das dem Zuschauer von der Leinwand entgegenschwappt, wird er deshalb nur höchst selten irritiert, nachdenklich geworden über Schuld und Vergebung, Freiheit und Verantwortung nach Hause entlassen. Kaum je wird er statt mit einem allfälligen Happy End oder genretypischen (von der ,normalen' Option auf ein Sequel geforderten) Weiterleben des Bösen konfrontiert mit einem profunden Leiden an ihm oder mit Durchbrechungen der Macht des Bösen, welche ihm insofern etwas zumuten als sie die Bürde der Verantwortung für das Böse und die Forderung nach einer Entscheidung gegen dieses nicht ausblenden.

Von exemplarischer Qualität für eine Auseinandersetzung mit dem Bösen im letztgenannten Sinn ist Robert Bressons "Das Geld" (1982), ein nicht zuletzt auch durch seine lakonische Inszenierung beklemmend-klaustrophobisches Kammerspiel, das wie ein Scharnier die vergangene und die gegenwärtige Generation des religiösen Films verbindet. Auf meisterhafte Weise thematisiert Bresson hier die komplexen Zusammenhänge von persönlicher Schuld und einem Bösen als "strukturales Geschehen" 57 - und ganz verhalten auch die Hoffnung auf seine Überwindung: Durch Falschgeld, das man dem einfachen Tankwagenfahrer Yvon Targe unterschiebt, wird eine Lawine des Bösen losgetreten. Verhärtet durch seine ungerechtfertigte Verurteilung obgleich nur , auf Bewährung' - weigert sich Yvon, seinen Arbeitgeber

56 Vgl. J. L. Duhourq, "Darstellung und Deutung des Bösen in der Filmkunst von heute“, in: Concilium 6 (1970) 445-449; M. Schlappner, Das Böse und der Film (Anm. 46).

57 Vgl. J. Gründel, Art. „Das Böse“, in: Ch. Schütz (Hg.), Praktisches Lexikon der Spiritualität, Freiburg i. Br. 1992, 167-169, hier 168. 
um Wiederanstellung zu bitten. Stattdessen beteiligt er sich an einem Banküberfall, dessen Mißlingen ihn ins Gefängnis bringt. Nachdem so Yvons kleinbürgerliche Existenz zerstört ist, stirbt während seiner Haftstrafe seine Tochter, und zuletzt verläßt ihn auch noch seine Frau. Bei einem Selbstmordversuch wird er gerettet und gerät, zurück im Gefängnis, unter den Einfluß seines neuen Zellengenossen, eines nihilistisch-zynischen jungen Intellektuellen. Fast wie ein ,dunkles' Alter ego verleiht dieser Yvons dumpfer Verzweiflung rationalen Ausdruck im Geiste von Dostojewskijs Iwan Karamasow (Iwan - Yvon!?), der sich angesichts all der unschuldig Leidenden von Gott und der in ihm begründeten moralischen Ordnung losgesagt hat.

Unmittelbar nach der Haftentlassung begeht Yvon einen ,sinnlosen' Mord an einem Hoteliers-Ehepaar. Einer alten Frau, der er folgt und die ihn aufnimmt, erzählt er seine Untat (und wohl auch seine Lebensgeschichte). Auf ihre Frage nach dem ,warum?' weiß er lediglich ein: "Es hat mir Spaß gemacht." Daß er sich freilich an "alle Einzelheiten" seiner Tat erinnern kann und bemerkt, daß die Opfer "scheußlich" aussahen, deutet an, daß ihm gleichwohl nicht alles menschliche Fühlen abhanden gekommen ist. Die Frau reagiert überraschend, und das vertieft das fast zärtliche Vertrauensverhältnis zwischen ihnen: "Ihnen wird vergeben werden. Wenn ich Gott wäre, wenn es nur nach mir ginge, dann würde ich jedem vergeben." Um so erschreckender ist das Ende: Eines Nachts dringt Yvon in das Wohnhaus der Frau ein. Als sie auf seine Frage "Wo ist das Geld?" schweigt, erschlägt er auch sie, wie zuvor schon ihre ganze Familie, mit einer Axt. Damit wird das schaurige ,Gebet' ${ }^{\prime}$ des Mithäftlings Wirklichkeit, der Yvon beschwörend eingeflüstert hatte: „Oh Geld, du sichtbarer Gott! Was würden wir nicht in deinem Namen tun!" - Doch der Film endet nun eben nicht mit dem Blick auf das Mordwerkzeug, als dieses ins Wasser geschleudert wird. Nachdem das einzige Indiz beseitigt ist, könnte Yvon mit dem Morden fortfahren - wie später "Henry", der Serienmörder (s. u.). Doch er geht in eine Gaststätte und gesteht einem zufällig anwesenden Polizisten seine Untaten.

Stets wurden in Bressons vorangegangenen Filmen seine Helden "mit den Kräften des Bösen konfrontiert", und es gab "Erlösung", allerdings "nie im Erbauungsstil, sondern asketisch und verhalten".58 Das Ende seines letzten Films ist düster wie nie zuvor. Man könnte hier das endgültige Scheitern der bei Bresson immer aufs neue auf die Probe gestellten christlichen Hoffnung vermuten, jener Hoffnung, daß erfahrene Liebe den Kreislauf des Bösen zu durchbrechen und erfahrene Vergebung eigenes Vergeben in Gang zu bringen vermag. ${ }^{59}$ Das

58 A. Eichenberger, "Religiöse Dimensionen im neuen Film“, in: film-dienst 30 (1977) Nr. 20, 4-6, hier 5.

59 Vgl. P. Vardy, Puzzle of Evil, 182. 
Verzeihen der alten Frau und ihre stille Liebe zu Yvon, die dieser mit zärtlichen Gesten erwidert, sind aber zweifelsohne ein solches Gnadengeschenk der Vergebung, selbst wenn es erst nach der letzten Mordtat Früchte zu tragen beginnt. Schon deshalb wäre es zu kurz gegriffen, sähe man das Böse hier mit Blick auf die zerstörerische Dynamik des Geldes "ganz in den abstrakten gesellschaftlichen Mechanismus selbst verlegt "60, in einen "anonymen Proze ${ }^{\prime \prime}$, dem Yvon "wenigstens eine persönliche Schuld abtrotzen" will.61 Yvons Handeln im Dienste des sichtbaren Gottes ,Geld' gerät vielmehr zu einem dumpfen Aufstand gegen den unsichtbaren Gott. Die Revolte kulminiert im letzten Mord, dem an der Liebenden und Verzeihenden, doch dieser Mord bricht dem Bösen die Spitze, vielleicht eben weil damit die seitens des Opfers zugesagte Vergebung eine allzu bestürzende Aktualität gewinnt. In der Bereitschaft, die Konsequenzen seiner Taten auf sich zu nehmen, findet Yvon zur religiösen Ordnung zurück.62 Wenn er sich nach seinem ,sinnlosen' Morden ohne äußere Not der Polizei stellt, wird etwas von der Freiheit und Fähigkeit des Menschen sichtbar, die Ketten des Bösen, die ihn gefangenhalten, aufzubrechen: mit dem freiwilligen Bekenntnis der Untaten wird Schuld anerkannt und so das Böse als Böses qualifiziert. Damit ist der erste Schritt einer Umkehr vollzogen, welche einer Vergebung Raum schafft, die den Tod transzendiert.

Wie in vielen seiner Filme erzählt Bresson in seinem fragmentarisch-elliptischen Stil das Entscheidende, hier das Bekenntnis, fast beiläufig, wenn er es nicht sogar ganz ins Indirekte, in den Raum außerhalb der Bilder verweist. Vielleicht spürte Yvon die Nähe Gottes im Angesicht der ihm vergebenden Frau. Mit seinem Geständnis "wagt" er jedenfalls "die pascalsche Wette auf seine [Gottes] unsichere und ungesicherte Existenz. “63 Letztlich thematisiert "Das Geld“ das Böse somit doch sub specie Dei im Spannungsbogen von Verhängnis und bewußter Entscheidung gegen das Gute. In dem Maße wie die Anwesenheit von Freiheit spürbar wird, rückt es ein in einen religiös qualifizierten Zusammenhang von Schuld, Vergebung und Gnade. Wie Yvons Weg zeigt, hält dabei die Freiheit zum Bösen immer auch virtuell die Möglichkeit der Umkehr in sich bereit, daß der Mensch also selbst (mit Hilfe der Gnade) eine Durchbrechung der vielleicht heillos geglaubten Schuldverstrickung anzubahnen vermag.

$60 \mathrm{~K}$. Visarius, "Ist das Böse noch zu retten?", in: Die Ästhetik des Bösen im Film (Anm. 24), 3-7, 6; vgl. auch: M. Josuttis, "Die Unerkennbarkeit des Bösen", in: ebd., 10-16, 16.

61 K. Visarius, ebd. - Selbst in Martin Scorseses "Good Fellas“ (1990), der wohl am radikalsten diese „zerstörerische Dynamik des Geldes“ zeigt, sind die Menschen nicht aus ihrer Mitverantwortung für das Böse, das sie tun, entlassen.

62 Zum Zusammenhang von Bekenntnis - Verantwortung - Freiheit in der religiösen Diskussion des Bösen vgl. P. Ricoeur, Schuld, Ethik und Religion (Anm. 21), bes. 388f.

63 P. W. Jansen, Schwarze Engel (Anm. 42), 38. 
Zwischen Bressons wie immer formal sehr strengem Alterswerk und dem grellen Traktat über Schuld und Erlösung, den zehn Jahre später Abel Ferrara mit "Bad Lieutenant" (1992) in Szene gesetzt hat, liegen zweifelsohne Welten. Aber gerade weil sie auch manches verbindet, im Thematischen wie im Formalen (z. B. lange Einstellungen, Bevorzugung der Halbtotalen, Ellipsen), läßt sich im Vergleich dieser beiden Filme erkennen, welche Wandlungen mit dem Lebensgefühl des Publikums auch der Film von religiöser Valenz innerhalb nur einer Dekade durchlaufen hat.

Trotz seines bisweilen recht plakativen Gestus und seiner Härte verdient "Bad Lieutenant" Beachtung als eindringliche Studie, die das Böse in einem christlich, ja förmlich ,orthodox' katholisch konturierten Horizont von Freiheit, Gnade, Umkehr und Erlösung zu vermessen sucht. Ferrara ist in seinen Rekursen auf die Heilsgeschichte um einiges deutlicher als Bresson, so als wolle er lautstark protestieren gegen die postmoderne Verabschiedung der christlichen ,Meta-Erzählung', als wolle er gegenüber einem konturlosen Ozean des "Anything goes" und einem synkretistisch-eklektizistischen Religions-Mix darauf insistieren, daß diese nach wie vor eine sinngebende Orientierungs-Achse darstellt. Wie in dem Fragment einer Holographie ist die Meta-Erzählung in der Geschichte, die Ferrara erzählt, eingeschlossen: Der namenlose New Yorker Cop, den die Credits nur als „B. L.“ (für „Bad Lieutenant") führen, konnte dem Bösen, das im Dickicht der fast apokalyptisch anmutenden Megalopolis auf ihn einströmt, nicht widerstehen. So glitt er irgendwann einmal selbst hinüber in den Teufelskreis aus Drogen, Sex und Korruption, gegen den er sich eigentlich von Berufs wegen hätte anstemmen sollen. Anders als bei der schillernden Figur des Polizisten Hank Quinlan in "Touch of Evil" (1957/58), deren sinistre Seite Orson Welles in diesem klassischen Diskurs über das Böse erst allmählich immer deutlicher hervortreten läßt, qualifiziert Ferrara seinen „Helden' bereits im Titel als "bad". Das schließt freilich nicht aus, daß dieses Profil im Verlauf der Erzählung verschoben werden kann. Die sich immer rasanter beschleunigende Selbstzerstörung des B. L. durch wahllosen Konsum hoher Dosen von Drogen jeder Art, durch Wettleidenschaft und - aus Angst vor schlimmen Träumen? - Schlafentzug mutet fast an wie eine (unbewußte?) Illustration des klassischen Theologumenons, demzufolge der Mensch durch die Sünde versklavt wird (Joh 8,34) und in eine Unfreiheit stürzt, aus der er "nur durch die Gnade Gottes befreit" ${ }^{\prime 64}$ werden kann. Diese Gnade widerfährt nun auch dem B. L.: in Gestalt einer jungen Nonne, die in einem schier übermenschlichen - in seiner Geradlinigkeit dramaturgisch überdeutlichen - Akt der Feindesliebe und radikalen Christus-Nachfolge (in bewußter Erinnerung an Jesu "Vater, vergib ihnen, denn sie wissen

64 K. Rahner, Art. "Sünde, dogmatisch" in: Lexikon für Theologie und Kirche, Bd. 9, Freiburg i. Br. 1986, 1177-1181, 1179. 
nicht, was sie tun") zwei Jugendlichen, die sie auf dem Altar ihrer Kirche brutal vergewaltigt hatten, verzeiht und sie gegenüber der Polizei deckt. Diese Nonne erscheint wie das von sämtlichen menschlich-allzumenschlichen Beimengungen purgierte Urbild all jener Menschen, die die Kraft haben, "to ,shine as lights in the world', to act as leaven in the lump, to try to stand out against the powers of darkness and to let their individual example as well as their love and commitment to others serve as an inspiration to those around them. "65

Die irritierende Begegnung mit dieser Frau läßt den B. L. nicht mehr los. Als er in seiner ,Abstiegsgeschichte' ${ }^{\prime}$ an einem völligen Endpunkt angelangt ist - wie Hiob auf seinem Misthaufen, nur daß er tatsächlich Schuld auf sich geladen und sich selbst ruiniert hat -, erlebt er in eben der Kirche, in der zuvor die Nonne vergewaltigt worden war, eine Christusvision. (Stellt man einmal das unangenehme "Deusex-machina"-Gefühl, das einen hierbei beschleichen mag, zurück: diese Vision wäre wohl eindringlicher, manifestierte sie sich nicht derart explizit im Bild, wäre der vom Kreuz herabgestiegene Erlöser nur für den B. L., nicht aber auch für den Zuschauer sichtbar.) Unter Tränen und einem fast unmenschlichen Heulen bricht aus dem am Boden Liegenden eine abgründige Klage ${ }^{66}$ hervor: "Wo warst Du? Ich habe so viel Böses in meinem Leben getan. Ich wollte gerecht sein, aber ich war zu schwach. Hilf mir! Warum sagst du nichts? Wo warst Du?" Und dann plötzlich der Umschlag: "Vergib mir! Vater, vergib mir!" Bei den letzten Worten kriecht der B. L. auf den unbeweglich und wortlos verharrenden Gekreuzigten zu; wie der verzeihende Vater auf Rembrandts berühmten Gemälde vom "Verlorenen Sohn“ streckt ihm Christus seine Hände entgegen und hält ihn - dann verschwindet er.

Indem er es im Bekenntnis vor Gott stellt, hat der B. L. also nicht einfach nur das Böse seines Tuns erkannt, sondern als Schuld anerkannt. Sein anfänglicher Vorwurf, daß Gott sich nicht gezeigt habe - die klassische Theodizee-Problematik -, seine Klage über die Gottverlassenheit weicht der Anerkennung der Eigenverantwortung, die sich im reuevollen Rufen nach Vergebung ausdrückt. In dem verzweifelten Gewahrwerden und Bekenntnis seiner Sündhaftigkeit wird sichtbar, daß der von ihm zuvor gerne bespöttelte Glaube für den B. L. nie wirklich aufgehört hatte, eine Realität zu sein. Dieser Glaube war verloren, aber als solcher konnte er wiedergefunden werden. Als dem B. L. nun kurz darauf die beiden Vergewaltiger und Kirchenräuber verraten werden, bringt er sie nicht hinter Gitter, sondern setzt sie in einen "Greyhound"Überlandbus. Sein ganzes, durch einen großen Drogendeal erworbenes

65 P. Vardy, Puzzle of Evil (Anm. 22), 179.

66 Zur religiösen Signifikanz der Klage im Kontext von Schuld und Vergebung vgl. P. Ricoeur, Schuld, Ethik und Religion (Anm. 21), 391; ders., Evil (Anm. 16), 200. 
Vermögen, etliche tausend Dollar, die er dringend gebraucht hätte, um einen Teil seiner Wettschulden zu begleichen und so seinen Kopf noch einmal aus der Schlinge zu ziehen, gibt er den Jungen als eine Art Startkapital für eine neues Leben mit auf die Reise. Wenig später wird er von unbekannten Tätern auf offener Straße erschossen.

Daß der B. L. die Vergewaltiger laufen läßt - allerdings zielgerichtet: hinaus aus dem Sumpf - und sie obendrein noch reich beschenkt, was sie, die eben noch um ihr Leben fürchteten, völlig irritiert über sich ergehen lassen, kann auf einer ersten Ebene so gelesen werden, daß der B. L. (wie Ferraras Figur des Frank White) wenigstens einmal in seinem Leben noch etwas Gutes tun will, weiß er doch dieses Leben bereits an einem seidenen Faden hängen: wenn nicht die Wettschulden, so werden ihn in Kürze die Drogen ins Grab bringen. (Die Vision deutet an, daß sein exzessiver, selbstmörderischer Drogenmißbrauch vielleicht seine tiefen Schuldgefühle hatte niederhalten sollen.) Nun aber zu meinen, der B. L. lasse in der Hoffnung, daß damit auch ihm vergeben wird, einfach bei nächster Gelegenheit jemandem gegenüber Gnade walten, gleich ob er diese verdient oder nicht, wäre doch zu eindimensional. Die selbstlose Handlung, dieses Tun des gänzlich Unerwarteten ist zum einen Ausdruck und Bestätigung der im Schuldbekenntnis anerkannten und insofern auch wiedergewonnenen Freiheit des Handelns ${ }^{67}$; zum anderen ist diese Aktion aber keineswegs so unmotiviert und absurd, wie sie zunächst erscheinen mag: Was der B. L. in der Kirchen-Vision für seine eigene Person anerkannt hat, daß er nämlich nicht nur ,Opfer der Verhältnisse', sondern auch verantwortlicher Täter ist, dieselbe Gleichzeitigkeit, nur in veränderter Gewichtung, wird er auch bei den Vergewaltigern gewahr: Er erkennt in den ebenfalls schon tief von den Drogen gezeichneten, offensichtlich durch sie in ihrer psychisch-geistigen Entwicklung und Wirklichkeitswahrnehmung gestörten Tätern auch die Opfer. Als die beiden Jungen wie gefangene scheue Tiere zittern, ahnt man, daß ihre Schuldfähigkeit eingeschränkt ist, daß sie ihre Untat subjektiv wohl so erlebt haben, wie sie inszeniert ist: als einen schrillen Videoclip, in dem sie mitspielen. Da der B. L. die eigene Umkehrbewegung nicht mehr vollenden kann, will er wenigstens die ihm widerfahrene Gnade in einen starken UmkehrImpuls für die anderen umsetzen und schickt sie gewaltsam aus dem Höllenkreis der Stadt hinaus: Indem sich der Blick des B. L. auf den Nächsten öffnet und er nicht solipsistisch bei sich selbst verharrt, indem er die auch ihm unverdient widerfahrene Gnade weiterschenkt, vollendet sich die Metanoia.

Gegen die ,easy pleasures', gegen die einigen Spielarten postmoderner ,Religiosität' erstrebenswert erscheinenden ,spirits', welche zwar gelegentlich den Alltag bereichern, aber zu nichts verpflichten, ruft Ferrara in der Christus-Vision nachdrücklich das Kreuz in Erinnerung:

67 Vgl. P. Vardy, Puzzle of Evil (Anm. 22), 43f. 
das Kreuz als Zeichen des Schmerzes und des Leids, aber auch als Zeichen dafür, daß man selbst "in der äußeren Niederlage, im scheinbaren Scheitern, doch den Sieg "68 behalten kann. Durch das Schuldbekenntnis hat der Tod für den B. L. seinen Schrecken verloren, auch wenn die Umkehr nur mehr im Ansatz ausgeführt werden kann. Was er leisten konnte, ist eine Bewegung, wie sie - natürlich unter anderem Vorzeichen - Georges Bataille für die Erlangung einer "neuen Unschuld" beschrieben hat: im "Durchgang durch das Heulen und Zähneklappern der Schuld"69, in der existentiellen Anerkennung der Freiheit zum Bösen und damit der Verantwortlichkeit für dieses, wendet sich das heillose Getriebensein, wird die Freiheit auch zum Guten - bei Bataille zum ,Bösen' - wiederentdeckt. So findet der B. L. Erlösung, die durch den irdischen Tod nicht mehr entwertet werden kann.

Ein Film wie "Bad Lieutenant" erinnert in mancher Hinsicht an Ingmar Bergman - thematisch wie in der Schonungslosigkeit seiner Bilder, die im Kontext der heutigen Wahmehmungskonditionen wohl eine ähnlich aufwühlende Wirkung haben wie einstmals manche Sequenzen in "Das Schweigen" (1965), "Die Stunde des Wolfs" (1966) oder "Schande" (1968). Das Rätsel des Leids, die Vermengung des Bösen mit dem Guten, das Schweigen Gottes angesichts der Präsenz des Bösen in der Welt: diese großen Themen Bergmans ${ }^{70}$ sind nicht verschwunden, aber sie haben ihr Äußeres gewandelt. Wo dem Schweden oft nur schwache Hoffnungsfunken bleiben, etwa einfach das 'Trotzdem' des Weiterlebens, des Weitermachens (wie am Ende von "Licht im Winter", 1961), wo es bei ihm meist nur kleine Zeichen der Läuterung und nur Spurenelemente eines Guten, das aus dem Bösen hervorbricht, gibt, ${ }^{71}$ da arbeitet der Italo-Amerikaner mit einem vergleichsweise groben Pinsel. Immerhin vermeidet aber auch Ferrara billigen Trost, wo es ihn nicht geben kann: Unter der nicht geleugneten Macht der Verhältnisse und unter der Last der aufgehäuften Schuld gelangt Umkehr nicht über erste Aufbrüche hinaus, ereignet sich Erlösung nur durch den Tod hindurch. In dieser Hinsicht ahnelt das Schicksal von Ferraras "Bad Lieutenant" - und auch das seines "King of New York" - der Geschichte des bezahlten Killers in Alan Barons "Blast of Silence" (1960), der aus dem Kreis des Verbrechens aussteigt und dies mit seinem Leben bezahlt. Auch Bressons Figur des Yvon Targe scheint einen Vorläufer zu haben: sie erinnert an den Rebellen gegen jede Moral in der metahistorischen Episode von Pier Paolo Pasolinis "Porcile" (1969), der am Ende offensichtlich freiwillig in die durchsichtige Falle der Obrigkeit tappt und damit sein Schicksal besiegelt: Nachdem er trotzig, jedoch mit tränenerstickter Stimme, die die ostentative Geste des

68 J. B. Hygen, Art. „Böse, Das“, in: Theologische Real-Enzyklopädie, Bd. 7, Berlin-New York 1981, 8-17, hier 16.

69 G. Bergfleth, Souveränität des Bösen (Anm. 5), 220.

70 Vgl. A. Schillaci, „Bergman's Vision of Good and Evil“, in: J. C. Cooper/C. Skrade (Hg.), Celluloid and Symbols, Philadelphia 1970, 75-88.

$71 \mathrm{Vgl}$. ebd., 83ff. 
Aufbegehrens untergräbt, bekannt hat: „Ich ermordete meinen Vater, ich $a ß$ Menschenfleisch, ich zittere vor Freude", wird er bei lebendigem Leib den wilden Tieren zum Fraß vorgeworfen.

"Blast of Silence“ und "Porcile“ rechnen insofern noch zum ,zeitgenössischen' Film, als beide (wohl nicht zufällig: eben im Kontext der neuen Frage nach dem Bösen und nach Erlösung) vielerorts erst in den letzten Jahren in die Kinos kamen. In beiden Werken wird durch Anspielungen auf die Passionsgeschichte der Hoffnung Ausdruck gegeben, daß selbst die größten Untaten, die den Menschen von seiner eigentlichen Bestimmung entfernen, Vergebung erfahren können, sobald in Freiheit der Weg aus dem Bösen heraus eingeschlagen wird, selbst wenn auf ihm nur mehr wenige Schritte getan werden können. Dies zeigt auch die georgische Regisseurin Lana Gogoberidse an der Figur des stalinistischen Offiziers und Kommandeurs einer ,Todesschwadron' in "Der Walzer auf der Petschora" (1992): in der Begegnung mit dem Kind deportierter ,Volksfeinde' macht dieser eine innerliche Wandlung durch und stellt schließlich Menschlichkeit vor Pflicht. Damit unterschreibt er zwar sein eigenes Todesurteil, doch er hat einen Frieden gefunden, der dieses überdauert. - Wie hier warten auch in einigen anderen Filmen Umkehrbewegungen, die von den Figuren nicht mehr vollendet werden können, darauf, vom Zuschauer zu Ende gedacht $\mathrm{zu}$ werden. - Zwei weitere Beispiele: Angesichts der Reue und tiefen Erschütterung des jungen, nur eingeschränkt schuldfähigen Mörders in Krzysztof Kieslowskis „Dekalog V: Ein kurzer Film über das Töten“ (1987) hofft der Zuschauer, ja ist sich fast gewiß, daß dieser im Himmel einen gnädigeren Richter finden wird als auf Erden, wo er am Galgen endet. Und ähnlich hofft er auch für die anfänglich nur von 'Nächstenliebe', dann zusehends von Geldgier motivierte Engelmacherin in Claude Chabrols "Eine Frauensache" (1988), deren stetig gewachsene Verhärtung des Herzens in der Nacht der Todeszelle aufbricht und sich in einem blasphemischen Gebet entlädt. Ihr ist Gott wieder eine Wirklichkeit geworden, selbst wenn sie in ihrer Todesangst nur Worte einer in Fluch und Schmähung transformierten Klage findet.

Es wäre deprimierend, würde sich immer ein dunkler Vorhang über die Hoffnungsspuren senken. Natürlich ergeht es auch im Kino vielen, die ,umgekehrt' sind, wie dem „Verlorenen Sohn“ der Bibel, für den nach seiner Wende zum Guten ein Fest gefeiert wird und der dann noch ein ganzes Leben vor sich hat. Wohl die beliebteste Metapher des Films hierfür ist die Reise - die Reise "out of the dark and into the blue“ (Neil Young). Die Fahrt hinaus in eine neue Zukunft ist ansatzweise schon bei den beiden Freigelassenen in "Bad Lieutenant" präsent. Besonders manifest wird sie etwa am Ende von Sean Penns (überhaupt stark mit religiösen Motiven durchsetzten) "Indian Runner" (1991) ${ }^{72}$

72 Vgl. zu diesem für unsere Thematik sehr interessanten Film: Vf., „Nach dem Sündenfall. Religiöse Momente in Sean Penns ,Indian Runner“", in: film-dienst 45 (1992) Nr. 2, 8-10. 
und in der Schlußsequenz von Pavel Lungins "Luna Park" (1992), einer fast idealtypisch konstruierten Hoffnungsgeschichte über die Wandlung eines gewalttätigen, haßerfüllten und ideologisch verblendeten Jugendlichen, der in der Suche nach seinem Vater der empfindsame Mensch wird, der er insgeheim schon immer war.

\section{Abwesenheit des Guten - Abwesenheit Gottes?}

Es gehört wohl zu den ,Zeichen der Zeit', daß heute nicht Filme wie die letztgenannten, mit ihren mehr oder weniger verhaltenen Bildern der Ermutigung, zu ,Kultfilmen' avancieren, sondern stattdessen ein Film, bei dem die Reise am Ende nur eine Reise zu neuen Verbrechen ist. Die Rede ist von John McNaughtons "Henry, Portrait of a Serial Killer" (1986), einem wahrlich erschreckenden, trostlosen Film: Henry, der in seiner Kindheit schwer traumatisierte Titelheld, der nach der Ermordung seiner Mutter immer weitere Frauen tötet, ist völlig eingeschlossen in Haß und (unterschwelliger) Angst. Selbst die leise Hoffnung auf einen reinigenden Schock, die keimt, als er in einem furchtbaren Blutbad seinen Mordgefăhrten Otis erschlägt, weil dieser blutschänderisch seine Schwester zu vergewaltigen sucht, wird zerstört. Henry fährt mit der Geretteten zwar hinaus aus der Stadt, doch am nächsten Morgen verläßt er alleine das Motel. Irgendwann hält er auf freier Strecke und stellt eine große, blutige Reisetasche am Straßenrand ab. Irgendwelche Polizei-Aktivitäten, die seinem Morden Einhalt gebieten könnten, sind nicht in Sicht.

Der Erfolg von "Henry" und etlichen anderen "Serienmörder'Geschichten in Film und Literatur läßt verschiedene Lesarten zu. Im Kontext der Renaissance des Bösen in unserem Fin de siècle steht die Serienmörder-Figur "geradezu in Reinkultur (...) für radikalen Individualismus und unbedingten Freiheitsdrang " und bringt insofern "den American Dream konsequent zu einem bizarr-grausamen Ende": er wird zum "tödlichen Vollstrecker der alten Ideale"73. In einer Umgebung, die durch die Paralysierung der Wertsysteme zusehends verwildert, gerät Selbstverwirklichung zur Triebverwirklichung; und diese radikalisiert sich dann beim Serienmörder in der lustvollen Destruktion. Hieraus mag ein Teil der dunklen Faszination, die vom Serienmörder ausgeht, resultieren: "Er ist der unbestrittene König im Reich der Triebe", in einem "Koordinatensystem, das zur Zeit extrem hoch im Kurs steht. " ${ }^{\text {74 }}$ Wie einstmals bei De Sade, den die Surrealisten ob seiner Entgrenzungs-Wut feierten, erreicht in einigen der neuen Figurationen des Serienmörders das Pathos einer absoluten Autonomie einen neuen

73 U. Genzler, „Kill and Thrill. Kriminalromane heute - der Serienmörder als Held“, in: Süddeutsche Zeitung, Nr. 186 v. 14./15.8.1993, 113.

74 Ebd. 
Gipfel: Freiheit - soweit diese bei den stets mitschwingenden psychotischen Zügen vorhanden ist - wird aktualisiert als Freiheit, das radikal Böse zu tun (bzw. zu imaginieren). Indem er bedenken- und schrankenlos der Neigung zum Bösen nachgibt, ist der Serienmörder die fleischgewordene Antithese zum christlichen Anspruch an die Freiheit, sich als Freiheit zum Guten zu bestimmen. Stand das Tun des Bösen bei De Sade noch im Zeichen des bewußten Aufstands gegen christliche Moral und aufklärerischen Humanismus, so fehlt den neuen Serienmördern jedoch eine solche Kontrastspannung. Während sich De Sade in offener, in philosophischen Intermezzi ausformulierter Empörung gegen Gott und die bürgerliche Domestikation der Triebe ergeht, ist bei den Serienmördern unserer Tage Gott überhaupt nicht mehr präsent, nicht einmal als Zielscheibe blasphemischen Spotts. Das Religiöse und mit ihm eine Moral, die auf der Grundentscheidung für das Gute gründet, sind in den modernen Konfigurationen völlig weggebrochen.

Ein Film wie "Henry“ ist sicher das krasse Gegenteil von dem, was man herkömmlicherweise unter einem ,religiösen' Film versteht. Als bestürzende Beschreibung dessen, wohin der Mensch geraten kann, ist er dennoch für die theologische Reflexion auf das Böse relevant, welche die conditio humana bis in ihre finstersten Winkel zu verfolgen hat. Er leuchtet die gerade im christlichen Anspruch an die Freiheit festgehaltene Möglichkeit der Entscheidung für das Böse aus. Wie früher Goyas "Desastres de la Guerra" hält auch "Henry“, in dem der Krieg als Feldzug des Einzelnen in die Städte verlegt ist, dem Menschen einen erschreckenden Spiegel vor. Besonders an der Figur des Otis, der, nachdem erst einmal die letzte Schwelle des Verbrechens überschritten ist, zur bloßen Triebbefriedigung, einfach zum Abreagieren tötet, zeigt McNaughton das Potential an atavistischer Grausamkeit, das im Menschen steckt und in Extremsituationen wie Krieg und psychischer Traumatisierung, oder in der Isolation der anonymen Gesellschaft, kurz: immer dann, wenn die normalen ,Sicherungen' ausfallen, freigesetzt werden kann (natürlich in ganz unterschiedlichen Formen und Intensitäten)..$^{75}$ Gegen solche Spiegel muß sich der Glaube an einen gerechten, liebenden Gott bewähren, auf Bilder, wie sie heute "Henry“ und eine ganze Welle neuer Gewaltfilme ${ }^{76}$ entgegenhält, muß er Antworten finden.

Wie schon Goya wollte auch McNaughton mit dem von ihm inszenierten Inferno des Bösen keineswegs der Lust am Grauen ${ }^{77}$

$75 \mathrm{Vgl}$. jetzt die große, bis in die Gegenwart geführte Bestandsaufnahme über dieses Potential H. P. Duerr, Obszönität und Gewalt. Der Mythos vom Zivilisationsprozeß, Bd. 3, Frankfurt/M. 1993.

76 Vgl. B. R. Rich, „Art House Killers“, in: Sight and Sound (1992) Nr. 8, $5 f$.

77 Mit dieser Funktion wäre auch das Genre des eigentlichen Horrorfilms, das hier nicht mehr diskutiert werden kann, zu eindimensional beschreiben. Vgl. dazu jetzt A. Schuller, "Gräßliche Hoffnung. Zur Hermeneutik des Horror-Films", in: ders./W. von Rahden (Hg.), Die andere Kraft (Anm. 8), 341-354. 
zuarbeiten. Unter Hinweis auf seine eigene Familie - einer seiner Brüder sei Krimineller geworden, ein anderer Anwalt - weist er den Gedanken der völligen Determinierung zurück ${ }^{78}$ und hofft, sein Film könne „auch abgebrühte Fans von Slasherfilmen wieder sensibilisieren, weil er wirklich das häßliche Gesicht des Todes zeigt.."79 "Henry" läßt den Kinogänger eine filmische "Säkularisation der Hölle"80 schauen und vermag ein derart tiefes "existentielles Mißbehagen" 81 zu entfachen, daß sich ihm nicht jeder aussetzen sollte. Doch indem er die oft verpanzerten Nerven des moralischen Empfindens bloßlegt, kann er dem ,Abgebrühten' zum Impuls für eine heilsame Selbstbefragung werden frei nach Goethe: „Wie hältst du es mit dem Bösen?". Allein des Schreckens wegen, den er verbreitet, sollte man ihn nicht verdammen. Vielleicht sollte man sich gelegentlich erinnem, daß früher Bilder wie die eines Hieronymus Bosch nicht in Museen, sondern in Kirchen hingen.

Funktional analog zur blasphemischen, provocatio ad salutem' findet in "Henry“ die Sehnsucht nach einer Uberwindung des Bösen keinen Raum mehr auf der Leinwand; der Gedanke an das Gute wird allein durch seine als schmerzhaft erfahrene völlige Abwesenheit (also rein ,ex negativo') beim Zuschauer wachgerufen. Vielleicht wird aber bei der radikalen Verweigerung der Hoffnung die Sehnsucht nach ihr sogar um so heftiger, um so quälender. Und vielleicht haben so gesehen selbst noch Übersteigerungen des Zynischen und Menschenverachtenden ins Groteske und Aberwitzige - wie Christoph Schlingensiefs Rassismus- und Perversitäten-Orgie "Terror 2000" (1992) oder Rémy Belvaux“ (u. a.) "Mann beißt Hund" (1992), wo ein Reality-TV-Team einen munter räsonierenden Serienmörder auf seinen Verbrechensstreifzügen begleitet und allmählich selbst in die Untaten involviert wird ihr Quäntchen ,Gutes': etwa wenn damit Selbstgerechtigkeit und vermeintliche moralische Sicherheit erschüttert werden, wenn einem Zuschauer plötzlich das Lachen, in das er sich geflüchtet hat, gefriert, oder wenn ein anderer sich dabei ertappt, momentelang mit dem Bösen sympathisiert zu haben.

78 Vgl. Th. Gaschler/E. Vollmar (Hg.), Dark Stars (Anm. 38) 87.

79 Zit. n. ebd. - Gegen G. Seeßlen, der diesem Film einen Versuch der "Desensibilisierung" unternehmen sieht: „Terror und Langeweile. Eine neue Form der Gewalt im Kino: "Henry', ,Mann beißt Hund und ,Romper Stomper"', in: Freitag, Nr.14 v. 2.4.1993, 9/11, hier 9 (mit seiner ,Gleichschaltung ${ }^{\prime}$ der im Titel genannten Filme als Vorzeichen eines „neuen Faschismus ", ebd. 11, greift dieser anregende Essay am Ende doch zu kurz).

80 Vgl. den kunstgeschichtlichen Aufriß von H. Sedlmayr, „Die Säkularisation der Hölle", in: ders., Der Tod des Lichts. Übergangene Perspektiven zur modernen Kunst, Salzburg 1964, 18-39.

81 M. Schlappner, Das Böse und der Film (Anm. 46), 148. 


\section{Abschluß}

Gegen alle Nivellierungen und Abdrängungen mahnt das Kino auf mannigfache Weise und mit allem Nachdruck die Wirklichkeit des Bösen an, ja derzeit ist es wohl die ,siebte' ${ }^{\prime}$ und jüngste der Künste, in der sich das Gefühl der tiefen Bedrohung und Verunsicherung am eindringlichsten artikuliert. Latent schwingt dabei freilich immer auch die Hoffnung mit, das allpräsente, numinose Böse in den selbstgeschaffenen, bei allem Grauen eben doch noch kontrollierten Bildern bannen zu können. Das Böse im Film mag bedrückende, ja furchtbare Züge tragen. Von christlicher Seite bleibt freilich immer zu hoffen, daß es "nicht das letzte Wort" 82 behält. Von daher versteht sich der Wunsch von Papst Johannes Paul II., den er 1980 bei seinem Deutschland-Besuch in seiner denkwürdigen Ansprache an Künstler und Publizisten richtete: Ohne die Legitimität und die Möglichkeiten der Darstellung des Bösen in den Künsten bestreiten zu wollen, hoffte er doch, daß dieses vor einen Horizont gestellt würde, der den Gedanken und die Möglichkeit des Widerstehens und der Umkehr einschließt, der etwas von der "Realität des Guten, der Erlösung, der Gnade des Heiles" durchscheinen läßt.83 Eine solche Transparenz meint keinesfalls, daß die Realität des Bösen irgendwie geleugnet oder dieses leichthin in einem größeren Guten aufgehoben würde. Darum wissen durchweg die künstlerisch herausragenden unter den Filmen, die Zeichen eines Glaubens daran setzen, daß das Böse nicht endgültig siegen wird, Zeichen, die oftmals ihre christliche Herkunft nicht verleugnen.

Etliche der hier näher diskutierten Werke stehen paradigmatisch dafür, daß das "neue Erscheinungsbild des religiösen Films" 84 eines ist, das sich in den meisten Fällen erst beim zweiten Blick - dann aber womöglich mit um so größerer Intensität - als ein solch ,religiöses' oder wenigstens für die theologische Reflexion relevantes zu erkennen gibt.

82 Papst Johannes Paul II., "Ansprache an die Künstler und Publizisten im Herkulessaal in München am 19. November 1980", in: Papst Johannes Paul II. in Deutschland. 15.-19. November 1980, Bonn Verlautbarungen des Apostolischen Stuhls 25A, 3. Aufl.), 186-193, hier 189.

83 Ebd. - Vgl. ăhnlich schon Papst Pius XII., „Der ideale Film. Ansprache am 21. Juni und 28. Oktober 1955 an Vertreter der internationalen Filmwirtschaft", in: Kath. Filmkommission für Deutschland ( $\mathrm{Hg}$.$) , Dokumente$ katholischer Filmarbeit, Düsseldorf-Oberhausen 1956 (Kath. Filmhefte 7), 22-24; vgl. auch 2. Vaticanum, Dekret "Inter Mirifica“, Nr. 7.

84 "The New Image of Religious Film" lautete das Thema der "Cavalletti Conference "93“ (Cavalletti Center/Albaner Berge; 23.-28. September 1993), bei der eine Zusammenfassung dieses Aufsatzes vorgetragen wurde. Eingeladen zu dieser Konferenz hatten: "Centro Interdisciplinare sulla Comunicazione Sociale (CICS), Pontificia Università Gregoriana, Rom; "Organisation Catholique Internationale du Cinéma“ (OCIC), Brüssel; "Center for the Study of Communication and Culture" (CSCC), London (jetzt: St. Louis). 
Viele, und oft gerade die irritierendsten Filme sind dicht am lebensweltlichen Kontext geführte Fortschreibungen der alten, ewigen Fragen um Gut und Böse. Indem sie sich ihnen nicht nur aussetzt, sondern sie auch gründlich und ohne vorschnelle Abstoßungen und Vereinnahmungen auf ihren Beitrag zur Bearbeitung des Problems des Bösen befragt, kann die Theologie etwas von der Welthaltigkeit zurückgewinnen, die sie in der Vergangenheit nicht selten verloren hat.

Das schließt natürlich - in Erinnerung an die oft unnachsichtigen Kommentare der alttestamentlichen Propheten zu ihrer Lebenswelt eine kritische Haltung ein; auch sie kann aber Zeichen des ernsthaften Dialogs sein. Kritik von christlicher Seite ist z. B. angezeigt, wenn die Darstellungen des Bösen umkippen in eine Woge des Irrationalismus, wenn sie zum Selbstzweck geraten und nur zur Befriedigung einer durch die ewige Faszination des Bösen angestachelten Schaulust dienen, oder wenn durch die spekulative Ausbeutung dieser Faszination sogar Aggression, Zynismus und Menschenverachtung gefördert zu werden drohen. Andererseits sollten Glaube und Theologie durchaus für jene Filme dankbar sein, die das Problem des Bösen nicht durch die eilfertige Befriedigung des Bedürfnisses nach klaren Antworten, nach Eindeutigkeit minimieren, sondern auf das verstörende Ineinander, auf die Ambiguität von Gut und Böse und so auf die Erlösungsbedürftigkeit des Menschen weisen, auf eine letzte Dimension, die außerhalb seiner Verfügungsgewalt liegt. Von produktiver Qualität für Theologie und Glaube sind deshalb letztlich alle Filme, die in der Darstellung und narrativen Bearbeitung des Bösen die Frage nach dem Humanum, nach Freiheit, Schuld und Erlösung, und damit letztlich die Frage nach Gott nicht zuschütten, sondern bedrängend gegenwärtig halten - und sei es allein vermittels der empfindlich spürbar gemachten Abwesenheit des Guten.

SUMMARY: Black depths and traces of hope. Facets of the evil in contemporary films

Against the background of the most recently highly discussed "renaissance of the evil " the fundamental principles and changes in the cinematic concepts of "the morally evil" since the beginning of the $80^{\circ} \mathrm{s}$ will be outlined and further discussed by means of selected examples (among othern by Robert Bresson, Abel Ferrara, David Lynch and Martin Scorsese). The cinema in its roll as a seismograph of the layers of conciousness and an institution of morality has reacted on the everywhere rising feeling of uncertainty and threat. The simple dualistic attempts to explain the evil by transfering it to the outside $(\mathrm{e} . \mathrm{g}$. into devils and demons, evil individuals or institutions) have been more and more replaced by investigations in the black depths of the soul. And this is related to a growing interference of the good and the evil. In a contrary movement series killer figures have recently won importance. By putting the central coordinate of freedom within the Christian discussion of the evil into the concrete form of the freedom of the radical evil, they "get things straight" in their own way. Their strange popularity stresses the urgency for theology to resume the often neglected question of theodicee. However, the horror scenarios are still 
confronted by more promissing cinema narratives - in the main tales of conversion - which back the opportunity to decide against the evil and sometimes talk in explicit religious outlines about sin and redemption.

\section{RÉSUMÉ: Gouffes et traces d'espoir. Les facettes du mal dans le film contemporain}

En ayant à l'arrière-plan le sujet depuis peu très discuté de la „renaissance du mal“, nous esquisserons les bases et les changements dans l'adaptation cinématographique du "mal moral“ depuis de début des années 80 et nous en discuterons de façon approfondie en nous référant à des exemples choisis (tels que ceux de Robert Bresson, Abel Ferrara, David Lynch et Martin Scorsese). Le cinéma, en tant que séismographe des êtats de la conscience et en tant $\mathrm{qu}^{\prime}$ "institution morale", a réagi au sentiment partout croissant de doute et de menace. Les tentatives à couleur dualiste comparativement simples pour expliquer le mal par le fait qu'on le transfère vers l'extérieur (par exemple en diable, démons, mauvais individus ou mauvaises institutions) ont été de plus en plus remplacées par la pénétration aux fins fonds de l'âme et - lié à cela - par un accroissement de l'interférence du bien et du mal. Dans un mouvement opposé, les figures de bandits des séries prennent de l'importance depuis peu. En concrétisant, au cours d'une discussion chrétienne sur le mal, la coordonnée centrale de liberté en tant que liberté du mal radical, ils se chargent, à leur façon, d'établir une situation claire. La theologie montre avec fermeté que leur popularité fait voir combien il est urgent d'acquérir une nouvelle réception de la question souvent évitée de la théodicée. Aux scénarios de films d'horreur font face bien sûr comme avant des histoires qui donnent de grandes espérances - le plus souvent des histoires de retour - des histoires qui misent sur la possibilité d'une décision contre le mal et qui, parfois, parlent de faute et de rédemption avec des contours religieux explicites.

RESUMEN: Vestigios del abismo y de esperanza. Facetas de la maldad en las películas actuales

Teniendo como trasfondo el ampliamente discutido, en el último tiempo, "renacimiento de la maldad" se discuten, en base a ejemplos seleccionados (entre otros de Robert Bresson, Abel Ferrara, David Lynch y Martin Scorsese), con profundidad las líneas básicas y los cambios del tratamiento fílmico del "mal moral" desde principio de los años 80 . El cine como seismógrafo de la situación de la consciencia e „instancia moral“ reaccionó al creciente sentimiento general de inseguridad y amenaza. Los intentos dualistas, comparativamente mucho más simples, de explicar la maldad situándola en el mundo externo (por ej. el demonio, instituciones o individuos perversos) fueron más y más reemplazados por un adentrarse en las oscuras profundidades del alma y unido a ésto - por una creciente interferencia de la bondad y la maldad. En un movimiento contrario ganan más importancia en el último tiempo figuras de asesinos en serie. En la medida en que se concretiza en éstos la discusión cristiana sobre la maldad en coordinadas centrales de la libertad como la libertad para la maldad radical, a su manera logran crear "un estado de cosas claro". Su popularidad indica, según la teología, la necesidad de la urgencia de retomar nuevamente la cuestión, frecuentemente evitada, de la teodicea. Frente a los escenarios de horror existen como siempre películas que nos muestran otros llenos de esperanzas que ponen el acento en la posibilidad de decisiones contra la maldad y que hasta ahora, en forma implícita, expresan perfiles religiosos de la culpa y la salvación. 